Article

\title{
Sustainability Performance Evaluation of Faceshield Bracket Manufacturing by Using the Analytic Hierarchy Process
}

\author{
Getasew Taddese ${ }^{1, *}$, Severine Durieux ${ }^{2}$ and Emmanuel Duc ${ }^{2}$ \\ 1 Addis Ababa Institute of Technology, School of Mechanical and Industrial Engineering, \\ Addis Ababa University, Addis Ababa P.O. Box 385, Ethiopia \\ 2 Clermont Auvergne INP, CNRS, Institut Pascal, Université Clermont Auvergne, \\ 63000 Clermont-Ferrand, France; severine.durieux@sigma-clermont.fr (S.D.); \\ emmanuel.duc@sigma-clermont.fr (E.D.) \\ * Correspondence: getasew.taddese@aau.edu.et; Tel.: +251-9-1263-8000
}

Citation: Taddese, G.; Durieux, S.; Duc, E. Sustainability Performance Evaluation of Faceshield Bracket Manufacturing by Using the Analytic Hierarchy Process. Sustainability 2021, 13, 13883. https://doi.org/10.3390/ su132413883

Academic Editors: João Carlos de Oliveira Matias and Paolo Renna

Received: 30 October 2021

Accepted: 9 December 2021

Published: 15 December 2021

Publisher's Note: MDPI stays neutral with regard to jurisdictional claims in published maps and institutional affiliations.

Copyright: (c) 2021 by the authors. Licensee MDPI, Basel, Switzerland. This article is an open access article distributed under the terms and conditions of the Creative Commons Attribution (CC BY) license (https:// creativecommons.org/licenses/by/ $4.0 /)$.

\begin{abstract}
Faceshield brackets were among highly relevant products manufactured in various workshops, including Sigma Clermont, during the outbreak of COVID-19 to tackle acute shortages of personal protective equipment. However, many of these products are yet to be checked for appropriateness in design, quality, safety, comfort, and overall sustainability performance which might lead to unknown damages to human health and the environment. Thus, the main objective of this study is to evaluate the sustainable performance of Faceshield bracket manufacturing. Appropriate data are collected from designers, machine operators, and supplementary data are utilized from experts opinions and literature. A total of 38 carefully selected indicator sets are utilized while applying multicriteria decision-making methodology (MCDM) of the analytic hierarchy process (AHP) to evaluate the sustainability performance of these manufacturing processes. Evaluation is performed to examine the processes' sustainability performance and associated indicator contribution based on the three dimensions. Results disclosed that 3D printing (score $=0.108$ ) showed better performance for the environment, and injection molding showed better economic and social performance, with scores of 0.1922 and 0.160 , respectively. A detailed contribution of each subcriteria for each sustainability dimension and each of the three processes as well as major contributing indicators are identified and discussed. Finally, overall performance was assessed using the total sum approach, and Borda count methodology and injection molding showed better sustainability performance in the manufacturing of Faceshield brackets considered with scores of 43 and 87, respectively. The authors believe that indicator selection approaches and overall methodology followed for this study will be relevant for future sustainability evaluation of engineering products.
\end{abstract}

Keywords: sustainability; sustainability assessment; sustainable manufacturing; multicriteria decision making; analytic hierarchy process

\section{Introduction}

The whole world, especially healthcare workers, faced a shortage of sufficient PPE and healthcare facilities during the unprecedented outbreak of coronavirus (COVID-19) which was a big challenge for all countries in the world. During this period, several 3D printing industrialists including Ford Motor company worked to manufacture 3D printed Personal Protective Equipment (PPE) [1]. As part of a solidarity effort of the CHU de ClermontFerrand, a university hospital center in Clermont-Ferrand, France, in its effort of preventing transmission of COVID-19 outbreak, Sigma Clermont successfully manufactured three different Faceshield brackets by using injection molding, 3D printing, and laser cutting, as shown in Figure 1. Enhancing such efforts helped to make an immediate delivery at least to local hospitals to tackle shortages of PPE. Such dispersed efforts of producing PPE in different workshops require proper knowledge of design procedure, consideration of mandatory features and preconditions for the intended purpose not to compromise the 
expected quality and effectiveness of protection (well fit for purpose), and necessity in considerations on sustainability aspects of manufacturing and using such products.

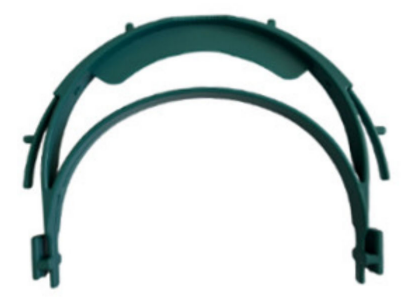

(a)

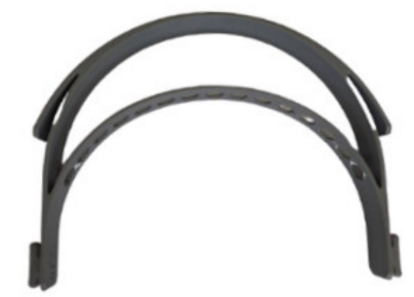

(b)

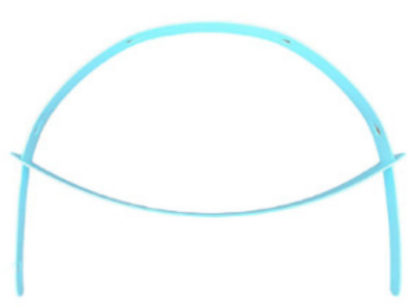

(c)

Figure 1. Faceshield brackets, manufactured by Sigma Clermont (a) Injection Molding, (b) 3D Printing, (c) Laser Cutting.

Based on recent developments, there is a highly emerging shift from design for manufacturing to design for additive manufacturing (DfAM) with a focus on sustainability. Furthermore, the life cycle aspect of products is recently becoming a major concern of many industries, original equipment manufacturers (OEMs), and researchers on the subject. Though the definition of sustainability and sustainable manufacturing itself varies, [2,3] provided a more meaningful definition of sustainability as analyzing both the environmental performance and the socioeconomic system considerations of manufacturing processes and systems. It can focus on either design of environmentally conscious production systems or design of closed-loop supply chains that consider the life cycle of a product from cradle to gate.

This study proposes a method for sustainability evaluation of manufacturing in three different methods. These methods are applied to the process used to manufacture Faceshield brackets at Sigma Clermont. The current and future relevance of this study is to develop a sustainability evaluation approach for such various components of Faceshield as a documentation initiative for sustainability performance of the manufacturing methods utilized. Moreover, we are in the era of considering manufacturing beyond the fabrication of a product, where it is becoming an integrated concept of all production phases, and there is an increased demand for products such as PPE which may lead to a trend in the manufacturing of Faceshield which is costly and unsafe. Here, we compare three processes with very different characteristics: one very industrial process and two processes for the general public. Indeed, the question of the dissemination of the means of production is important within the framework of Industry 4.0.

Table 1 represents selected important features for the three processes to assist decisionmakers to make judgments in alternative comparisons for judgments associated with the material utilized, product weight, manufacturing time, cost, and required training for skill enhancement.

Table 1. Important features of the three processes.

\begin{tabular}{cccc}
\hline Feature & Injection Molding & 3D Printing & Laser Cutting \\
\hline Material & $\mathrm{PP}$ & PLA & PP \\
Material format & Pellet & Filament & Plate \\
Material cost & $2.13 \mathrm{EUR} / \mathrm{Kg}$ & $30 \mathrm{EUR} / \mathrm{Kg}$ & $5.88 \mathrm{EUR} / \mathrm{g}$ \\
Weight/part & $36 \mathrm{~g}$ & $32 \mathrm{~g}$ & $13 \mathrm{~g}$ \\
Waste/part & $0 \mathrm{~g}$ & $4 \mathrm{~g}$ & $1.5 \mathrm{~g}$ \\
Manufacturing time & $1 \mathrm{~min} 12 \mathrm{~s} /$ part & $140 \mathrm{~min} /$ part & $1 \mathrm{~min} 25 \mathrm{~s} / \mathrm{part}$ \\
Machine cost & $20 \mathrm{EUR} / \mathrm{h}$ & $1 \mathrm{EUR} / \mathrm{h}$ & $5 \mathrm{EUR} / \mathrm{h}$ \\
Energy consumption & $500 \mathrm{Wh}$ & $375 \mathrm{Wh}$ & $52 \mathrm{Wh}$ \\
& Important & & Medium \\
Skill & Operator training 3 days & Weak & Operator training 30 min \\
& Technician training 1 year & & Technician training 2 days \\
\hline
\end{tabular}




\section{Test Case: Materials and Methods}

The manufacturing of Faceshield brackets used for this study was conducted using three methods of manufacturing: injection molding $\left(\mathrm{ALT}_{1}\right), 3 \mathrm{D}$ printing $\left(\mathrm{ALT}_{2}\right)$, and laser cutting $\left(\mathrm{ALT}_{3}\right)$. Each process is based on a specific application, material type, and requirements as it is applied to the manufacturing of the Faceshield bracket used for sustainability evaluation in this study. AHP is used for multicriteria decision analysis and aggregated evaluation of indicators which involves a definition of the decision tree, comparison judgment matrix, and calculation of aggregated criteria, subcriteria, sub-sub criteria, and alternatives.

Authors utilized aspects of the general sustainability assessment framework for sustainability performance of manufacturing processes as proposed by [4] which focuses on product level and considers the most relevant sustainable performance indicators for utilized processes and products adapted from a study by [5], as shown in Figure 2.

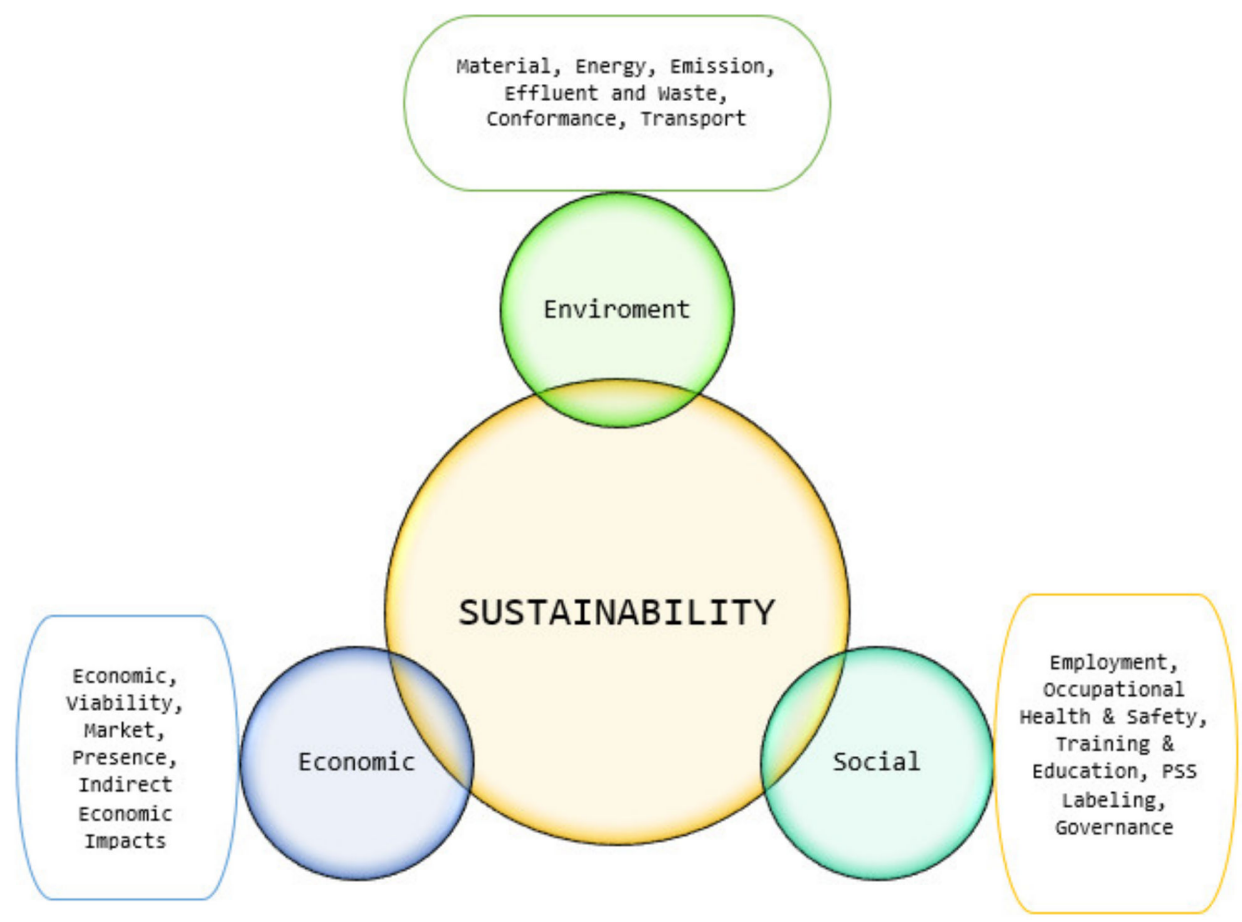

Figure 2. Proposed sustainability pillars and subcriteria for analysis.

\section{Methodology}

\subsection{Indicator Selection Strategy}

When products are manufactured for the market, product brands and specification details, the most important factors for product design and manufacturing are human (occupational) safety, weight, cost, the effect on the environment (post-use), wear resistance, ease of manufacturing, comfort, compatibility and other additional design features such as adjustable straps, fasteners, etc. This was used as initial consideration for indicator selection strategy through understanding design and innovation trends in Faceshield bracket and components manufacturing for various applications. Works of literature to date focus on materials used for medical equipment to keep their place in the market based on different considerations. Concerning material used, major criteria include price, versatility with type, availability measured depending on its abundance, mechanical behavior, ease of shaping to complex forms and features, density, and compatibility with the human body which may not cause an allergic effect [6-10].

The sustainability measure considers as much information as possible regarding the sets of performance indicators that will be used to measure overall sustainability performance. These indicators can be categorized into three major dimensions as environment, 
economic and social performances. Major criteria include comfort, cost, quality, durability, flexibility, style, time to market, waste, etc. Moreover, marketing authorization makes sure that the product is safe for human health and the environment during use and it does not create health, safety, and occupational risks during manufacturing or post-use. Data gathering was conducted by collecting quantitative measurements taken from designers and manufacturers of brackets by supplementing experts' opinions and literature surveys. Finally, the structuring of indicator sets is arranged based on 38 of the most preferred indicators (sub-sub criteria) among the 68 sustainability performance indicators proposed by [5]. Development of the 68 sustainability performance indicators was carried out through extensive review and assessment of the literature on sustainability, sustainable design, manufacturing, and additive manufacturing and its opportunity for realizing more sustainable products. This list contains a carefully identified and interpreted list of 29 indicators for the environment, 9 indicators for economic, and 30 indicators for social dimension. For this study, the selection of the 38 indicators was based on relevance and impact for sustainable performance of each of the three processes within this scope of this study. After identifying relevant indicators (sub-sub criteria) in this study, the weighting was performed by using the AHP method.

Exclusion of the other 30 indicators was based on the fact that either the indicator does not have direct relevance for sustainable performance of this specific Faceshield bracket manufacturing or has the same (positive or negative) effect in overall sustainability analysis. The 30 indicators were eliminated because their effect is negligible for the sustainability performance of the three processes. Considering different products and/or processes may include more indicators into analysis depending on their contribution. For this study, indicators from the environment (water, biodiversity, and product and service) and social dimension (marketing and communication and compliance to social standards) were excluded based on their relevance. Finally, the list of all included sub-sub criteria for each sustainability dimension is explained in Sections 3.2-3.4. Table 2 represents the category of selected subcriteria and sub-sub criteria for each of the three sustainability criteria. Environmental indicators are listed in material, energy, emission, conformance, and transport criteria. Economic indicators are listed in viability, marketing presence, and indirect impact criteria. Social indicators are listed in employment, health, training, product service and labeling, and governance.

\subsection{Subcriteria Contribution to Environment $\left(C_{1}\right)$}

\subsubsection{Material $\left(\mathrm{SC}_{1}\right)$}

The contribution of the material in this study is structured based on material consumption $\left(\mathrm{SSC}_{1}\right)$, material efficiency ( $\left.\mathrm{SSC}_{2}\right)$, availability $\left(\mathrm{SSC}_{3}\right)$, and recovery of material (SSC4). Material consumption refers to the total amount of material consumed to manufacture a single Faceshield bracket, which is approximated from the total weight of the bracket manufactured through each of the three processes. The efficiency of material utilization was calculated by subtracting the weight of the bracket from the total weight of raw material purchased. Currently, since there is no recycling, the possibility of determining/planning for recycling will help existing waste to re-enter the system to have better material efficiency. This means material efficiency can still be enhanced by introducing recycling. Material availability was also assessed. The raw materials used were propylene (PP) and Polylactic acid (PLA). The raw materials allow easy implementation, faster molding and printing, and less waste. PP was applied for injection molding and laser cutting and PLA was applied for $3 \mathrm{D}$ printing to manufacture the bracket. However, various alternatives to replace these materials include ABS, PETG, TPU95, etc., depending on the manufacturing method and application. 
Table 2. Category of subcriteria and sub-sub criteria.



\subsubsection{Energy $\left(\mathrm{SC}_{2}\right)$}

The contribution to energy was determined based on energy consumption $\left(\mathrm{SSC}_{5}\right)$ and utilization of renewable energy $\left(\mathrm{SSC}_{6}\right)$. Energy consumption can be considered as direct and indirect. In the manufacturing of the Faceshield bracket, energy is consumed in material extraction, processing, and transportation (which was not addressed in this study) but approximated consumption of energy consumption by machine is considered. To manufacture a single bracket, 3D printing uses a $150 \mathrm{~W}$ machine that is run for $2.5 \mathrm{~h}$ and power consumption of approximately $0.375 \mathrm{KWh}$, and a laser cutter uses a laser tube $(150 \mathrm{~W})$ with a total power of $2.5 \mathrm{KW}$, resulting in energy consumption of $0.052 \mathrm{KWh}$. Thus, energy consumptions of machine operation and material heating are of major interest. As an initiative for energy-efficient production, there is a high chance of utilizing a recycled PP and PLA, instead of virgin input, as a means to minimize direct and indirect energy consumption.

\subsubsection{Emission, Effluent, and Waste $\left(\mathrm{SC}_{3}\right)$}

The effect of EEW is connected with machines utilized, transportation, and mechanism of disposal [11-15]. The manufacturing sector contributed 19\% of the GHG emission (2013) in the economic activity of European countries [4]. Thus, advancements in technologies are helping minimize impact associated with EEW through minimized energy and resource consumption. Contributions of greenhouse gases (GHG) emission $\left(\mathrm{SSC}_{7}\right)$, primary air 
pollutants, PAPs $\left(\mathrm{SSC}_{8}\right)$ secondary air pollutants, SAPs $\left(\mathrm{SSC}_{9}\right)$, and waste $\left(\mathrm{SSC}_{10}\right)$ are considered in this category mainly associated with machines utilized, transportation, and disposal mechanisms. In the manufacturing of the bracket, a process-level GHG emission often occurs during material heating and extrusion, where the contribution to GHG emission is less as compared to raw material treatment, transportation, and compression. According to a study by [16], the conversion of methane $\left(\mathrm{CH}_{4}\right)$ is less than $0.1 \%$ and leads to neither significant emission of GHG nor energy savings and contributions during treatment; transportation is more than extrusion and recycling of PLA results in minimizing GHG emissions.

PAPs are contributed as direct emissions such as $\mathrm{CO}_{2}, \mathrm{SO}_{\mathrm{x}}, \mathrm{CO}$ and PM, VOC, etc., and SAPs such as smog, $\mathrm{SO}_{2}$, and other pollutants from NOX and VOCs. Heating of PLA to a temperature greater than $200{ }^{\circ} \mathrm{C}$ may be harmful to human health and more than 216 individual VOCs are released into the indoor air $[17,18]$. In injection molding, volatile emissions occur from the vents in heating or injection cylinders and molds. According to [19], the highest processing and decomposition temperatures for PP are $275{ }^{\circ} \mathrm{C}$ and $300^{\circ} \mathrm{C}$, respectively, but decomposition products do not form at or near injection molding temperature. For reference, the VOCs emitted ABS and HIPS range from 10 to $110 \mu \mathrm{g} / \mathrm{min}$ and PLA from 4 to $5 \mu \mathrm{g} / \mathrm{min}$ [19]. The injection molding process generates high environmental emissions during high temperature melting and in 3D printing during extrusion of the filament within the melting temperature ranges of $200^{\circ} \mathrm{C}$ to $318^{\circ} \mathrm{C}$ for PP. The selection of the filament material is an indicator for potential VOCs that would impact human health and working conditions such as proper ventilation in the case of laser cutting of plastics which may minimize the impact on the operators.

Concerning waste, for manufacturing using injection molding, there is no waste. However, there is an advantage of reusing wastes of PP from injection molding, which will significantly minimize the contribution of waste to the environment. The materials used in all three processes are recyclable and waste generation is limited, approximately $4 \mathrm{~g}$ for $3 \mathrm{D}$ printing and $1.5 \mathrm{~g}$ for laser cutting per Faceshield bracket. Moreover, the initiative to mitigate environmental impacts can be achieved more through energy-saving especially in the preparation and transportation of raw material.

\subsubsection{Conformance $\left(\mathrm{SC}_{4}\right)$}

Conformance is measured through monetary values of fines for non-compliance $\left(\mathrm{SSC}_{11}\right)$, the number of nonmonetary sanctions $\left(\mathrm{SSC}_{12}\right)$ for noncompliance with environmental regulations, and total environmental protection expenditures and investment $\left(\mathrm{SSC}_{13}\right)$. There is a variation among the two processes for compliance with social standards $[11,13,20,21]$. There is a good trend that PLA is made from renewable sources and contributes less to negative impacts to the environment and less chance for nonmonetary fines or sanctions during processing. Moreover, post-use processing could be possible through recycling for both processes.

\subsubsection{Transport $\left(\mathrm{SC}_{5}\right)$}

Transport considers contributions from the environmental impact of transporting products $\left(\mathrm{SSC}_{14}\right)$ and strategy of introducing efficient transportation mode $\left(\mathrm{SSC}_{15}\right)$. A $3 \mathrm{D}$ printing device can be implemented locally and make manufacturing closer to users of products which significantly shortens supply chains and cut down logistics and transportation costs in CM [13,21-25].

The environmental impact associated with transportation includes material and raw materials. The high infrastructure needs in injection molding demand transportation of raw materials and manufactured products to users which leaves this impact higher than 3D printing, which can be located near either the consumer or near the material source. Thus, with the costs of establishing infrastructures and Fab Labs, there is also a possibility of considering energy-efficient transportation near the user or material source. 


\subsection{Subcriteria Contribution to Economic $\left(C_{2}\right)$}

\subsubsection{Economic Viability $\left(\mathrm{SC}_{6}\right)$}

This considers contributions from a direct economic value $\left(\mathrm{SSC}_{16}\right)$ generated, cost $\left(\mathrm{SSC}_{17}\right)$ incurred throughout the product's life cycle, innovation $\left(\mathrm{SSC}_{18}\right)$ as expenditure on research and development, and benefit plans $\left(\mathrm{SSC}_{19}\right)$ such as possible financial assistance from the government or other sources. The value of the product can be seen from different perspectives or the possibility of including relevant features such as variations on thickness, weight, etc., and the possibility of enhancing features related to compatibility in size and shape and mechanical property. Evaluation can be given in these aspects of weight, thickness, size, shape, and property. The economic value of the bracket manufactured through these three processes depends on the scale of production. The higher economic value of bracket is injection molding followed by laser cutting than for 3D printing, which is economically valuable for small scale production. The $3 \mathrm{D}$ printing facility provides a higher chance for innovation and there is a chance of getting financial assistance from the government.

\subsubsection{Marketing Presence $\left(\mathrm{SC}_{7}\right)$}

The contribution to marketing presence is considered from standard entry-level wages $\left(\mathrm{SSC}_{20}\right)$, the policy of spending on locally-based suppliers $\left(\mathrm{SSC}_{21}\right)$, and hiring from the local community $\left(\mathrm{SSC}_{22}\right)$. It is a bit difficult to spend on locally-based suppliers for manufacturing using injection molding. However, if considering material development, PLA production using the fermentation process can engage many local raw material suppliers. Moreover, it is economically beneficial to center distribution nearby suppliers which will minimize costs and time spent in transportation to reach customers.

\subsubsection{Indirect Economic Impact $\left(\mathrm{SC}_{8}\right)$}

The indirect economic impact is measured through investment $\left(\mathrm{SSC}_{23}\right)$ and service primarily for public benefit and impact knowhow $\left(\mathrm{SSC}_{24}\right)$ towards job creations by suppliers, increasing productivity and business to business activity. AM helps to produce customized items or parts with multiple integrated components for better commercial benefit. AM also encourages entrepreneurship and product development due to the ease of producing a prototype just by printing a single piece of equipment rather than requiring a factory setup. It also encourages the creation of personalized products by just using 3D printers to test the customized products $[20,22]$.

Injection molding needs an industrial infrastructure of large machine tools which could benefit the public through commercial, in-kind, pro bono, or public good engagement. However, this is more expensive than a laser cutting facility, which needs the development of structure like Fab Lab, as compared to the least expensive method of 3D printing where there is no need for infrastructure development. Unlike injection molding, which is economically beneficial in mass production, 3D printing contributes less to economic impacts such as in jobs created by suppliers, productivity enhancement, and business-tobusiness activity.

\subsection{Subcriteria Contribution to Social $\left(C_{3}\right)$}

\subsubsection{Employment ( $\left.\mathrm{SC}_{9}\right)$}

The type of process has an impact on the type and required performance of manpower as an employee [26-30]. Thus, contribution to employment is determined from total workforce employment type ( $\left.\mathrm{SSC}_{25}\right)$, new employee hires and turnover as job creation $\left(\mathrm{SSC}_{26}\right)$, workforce safety and comfort through job security $\left(\mathrm{SSC}_{27}\right)$, and performance $\left(\mathrm{SSC}_{28}\right)$ based on employee skill, knowledge and competences.

The manufacturing of brackets does not require various employment types besides basic part design and machine operation. However, since sustainability issues consider lifetime aspects, the growing market opportunities of PLA and PP thermoplastic materials will involve various employment types. Thus, job creation and accessibility to the labor 
market are to be expected in applications using these materials. Moreover, according to estimates of European Bioplastics, by 2030, 300,000 highly skilled jobs will be created in the European bio-market, more than 10 times its current numbers.

Concerning human safety due to the emission of harmful chemicals, a process-related effect due to material used for human safety (operator) is not a problem as long as manufacturing is performed within proper ventilation. With poor ventilation, fumes from laser cutting of plastics affect machine operators. For the three processes, employee performance can be easily enhanced through operator and technician training limited to a few days. It is also possible to enhance through self-learning such as in 3D printing.

\subsubsection{Occupational Health and Safety $\left(\mathrm{SC}_{10}\right)$}

Major contributors considered for occupational health and safety (OHS) are injury rate $\left(\mathrm{SSC}_{29}\right)$ such as acute injuries, lost working days, and illness incident, as well as education $\left(\mathrm{SSC}_{30}\right)$ for prevention and risk control programs. The injury rate is significantly minimized in additive manufacturing methods since there is no continuous involvement of workers in processing and post-processing activities [24,31-34]. Thus, there is a minimized possibility of injury rate or work-related fatalities in 3D printing and laser cutting as compared to injection molding, which has shown a growing injury rate even with experienced workers mainly related to training and disregarding safety issues such as proper spacing, lighting, cleaning, etc. Thus, higher training and education are needed for injection molding for safety and better skill enhancement training for 3D printing to boost innovation.

\subsubsection{Training and Education $\left(\mathrm{SC}_{11}\right)$}

Average hours of training needed $\left(\mathrm{SSC}_{31}\right)$, skill management programs for enhanced career development $\left(\mathrm{SSC}_{32}\right)$, and regular performance and development reviews $\left(\mathrm{SSC}_{33}\right)$ are contributions analyzed for this subcriteria of the social dimension. Realization of the intended product requires training and education for specific skill, knowledge, or competence enhancement based on the type and total hours required depending on the type of manufacturing process. This is also related to continued employability and career development, and it could be given through company or self-training.

\subsubsection{Product and Service Labeling $\left(\mathrm{SC}_{12}\right)$}

Product and service (PSS) labeling consider customer satisfaction $\left(\mathrm{SSC}_{34}\right)$ through safety, comfort, better value, conformity ( $\mathrm{SSC}_{35}$ ) to customer needs and values $\left(\mathrm{SSC}_{36}\right)$ for the monetary value of fines for non-compliance to provisions and use of PSS. Manufacturing can be closer to users and can easily be built locally rather than large factories and the level of quality or comfort expected by users depend on their needs but based on the type of process measure of flexibility in adaptation work is very relevant to measure.

\subsubsection{Governance $\left(\mathrm{SC}_{13}\right)$}

The two contributions considered for governance are equity and fairness $\left(\mathrm{SSC}_{37}\right)$ concerning equal rights and freedom and efficiency $\left(\mathrm{SSC}_{38}\right)$ or the performance of an employee or a team. In raw material (PLA) development for 3D printing, there is a moral issue of spending on crops for bioplastics where there are many who need it for food. However, the ease of self-learning, cheaper price, and printing flexibility show equal rights and freedom for innovation and product manufacturing. As a method of enhancing the performance of an employee in a day, training in the company for injection molding and laser cutting but self-training for 3D printers is an opportunity to take.

\subsection{AHP Analysis}

\subsubsection{Approach}

Evaluating the sustainable performance of these processes is equivalent to evaluating the performance of the processes concerning all of these criteria. A methodological problem then arises to define the decision-making strategy that leads to an evaluation 
and a choice. To enable the decision-maker to make the right choice, several methods have been developed in the multicriteria context since the 1960s. These methods then help direct the decision-maker towards a judicious compromise rather than an often outdated optimum [35].

Currently, decision-makers have various MCDM methods to choose from in decisions on problems that involve multiple criteria. For example, the following methods have been developed in different periods having their features and objectives: SMART (1986), REGIME (1986), ORESTE (1980), VIKOR (1998), PROMETHEE I-II-III (1986), QUALIFLEX (1975), SIR (2000), EVAMIX (1982), ARAS (2010), Taxonomy (1763), MOORA (2004), COPRAS (1994), WASPAS (2012), SWARA (2010), DEMATEL (1971), MACBETH (1990), ANP (1996), MAUT (1976), IDOCRIW (2016), TODIM (1992), EDAS (2015), PAMSSEM I and II (1996), ELECTRE I, II and III (1990), EXPROM I and II (1991), MABAC (2015), CRITIC (1995), and KEMIRA (2014). Each method helps decision-makers to select the best alternatives among the different alternatives and has its features based on the independent and dependent attributes or criteria and whether or not the qualitative attributes should be converted into the quantitative attributes [36].

A very large number of multicriteria methods can be identified, which can be seen as a strength or a weakness [17]. This multiplicity of aggregation methods can be explained by the fact that no method completely meets the requirements expected by the user [37]. Thus, depending on how performance is aggregated, analysts will have to adapt their approaches. However, most of these methods belong to one of the following three operational approaches [38]:

- The single criterion synthesis approach;

- The synthesis outranking approach;

- The interactive local judgment approach with trial-and-error iterations.

Within the framework of this research work, we chose to place ourselves within the framework of the single criterion of synthesis approach to evacuate any incomparability. Preferences are then introduced a priori. They are aggregated into a single (value, utility) function which is then optimized. The main methods belonging to this approach are weighted sum, MAUT [39,40], SMART [41], UTA [42], TOPSIS [43], AHP [44] and G.P [45].

Since there are significant similarities between the various MCDM methods, it is difficult to compare AHP with all existing MCDM methods. However, comparisons of AHP with two of the recently introduced methods, the Best Worst Method (BWM) and a Step-wise Weight Assessment Ratio Analysis (SWARA), are reported here. The BWM helps decision-makers to increase the consistency and uniformity of MCDM methods and enough capability to determine the optimum results (even though various decision-makers forward different opinions) in a decision-making problem. Optimum results are acceptable by all decision-makers. Furthermore, both AHP and SWARA use pairwise comparison to express the relative comparisons to express the relative significance of the elements in a hierarchy, which is called the comparative importance of average value in the SWARA method. For the same number of criteria, the AHP method requires a significantly greater number of pairwise comparisons as compared to SWARA methods.

A large number of criteria may create possible inconsistency of performed comparisons. However, $\mathrm{AHP}^{\prime}$ s capability for consistency verification procedure is an advantage over the SWARA method, which does not have this capability [46]. Predefined scales (a nine-point scale) are used by the AHP method as reported in Table 3. However, the SWARA method has greater freedom to express judgments than the AHP method where a nine-point scale is used to make judgments [47]. SWARA was developed recently, where the relative significance and initial priority of the independent attributes are determined according to the opinion of the decision-maker, and then the relative weight of each attribute is determined before the priority and ranking of the attributes are done [36]. Thus, AHP was selected as an MCDM methodology for this study for the fact that it is one of the most powerful and easy to structure and solve the defined problem, and can per- 
form inconsistency verifications even if the judgments are made based on the predefined Saaty's scales.

Table 3. Fundamental comparison scale [47].

\begin{tabular}{ccc}
\hline $\begin{array}{c}\text { Intensity of } \\
\text { Importance }\end{array}$ & Definition & Explanation \\
\hline $1 ; 2$ & $\begin{array}{c}\text { Equal importance; weak } \\
\text { Moderate importance; } \\
\text { moderate plus } \\
\text { Strong importance; } \\
\text { strong plus } \\
\text { Very strong; very, } \\
\text { very strong }\end{array}$ & $\begin{array}{c}\text { Two activities contribute equally to the objective. } \\
\text { Experience and judgment slightly favor one } \\
\text { activity over another. }\end{array}$ \\
$5 ; 6$ & $\begin{array}{c}\text { Experience and judgment strongly favor one } \\
\text { activity over another. }\end{array}$ \\
$7 ; 8$ & Extreme importance & $\begin{array}{c}\text { its dominance is demonstrated in practice. } \\
\text { The evidence of favoring one activity over } \\
\text { another is of the highest possible order } \\
\text { of affirmation. }\end{array}$ \\
\hline
\end{tabular}

Since the goal of this study is to evaluate the sustainability performance of three methods in the manufacturing of Faceshield brackets, selection of performance indicators was based on relevance to sustainability, and the chance of proper data gathering. The basis for judgment by decision-makers is already presented in Section 3 based on data gathered from manufacturers and operators in conjunction with secondary data collected through literature about each process. The indicators' tree, Figure 3, shows the splitting of the problem in a hierarchy of criteria, subcriteria, and sub-sub criteria to simplify the overall evaluation. The first level contains 3 criteria, the second level contains 18 subcriteria and the third level contains 38 sub-sub-criteria.

Furthermore, determination of comparison values for the three criteria $\left(C_{1}\right.$ to $\left.C_{3}\right)$, the thirteen subcriteria $\left(\mathrm{SC}_{1}\right.$ to $\mathrm{SC}_{13}$ ), the thirty-eight sub-sub criteria $\left(\mathrm{SSC}_{1}\right.$ to $\left.\mathrm{SSC}_{38}\right)$, and the three alternatives $\left(\mathrm{ALT}_{1}\right.$ to $\mathrm{ALT}_{3}$ ) was decided based on the fundamental comparison scale as shown in Table 3 for its validated effectiveness in several applications and theoretical justifications which represents the fundamental scale of values, which are validated for effectiveness both in an application and theoretical justifications, to represent the intensity of judgments. These scales are used to determine how many times one criteria, subcriteria or alternative is larger than the other.

For the alternatives, approaches of adapting data collected from manufactured brackets, experts' judgments were carried out based on Table 4, which reports pairwise comparison judgments proposed by decision-makers as applied for each sub-sub criteria based on data from manufacturers, literature survey, and experience. The judgments made by the decision-makers for the three alternatives $\left(\mathrm{ALT}_{1}\right.$ to $\left.\mathrm{ALT}_{3}\right)$ are based on each of the sub-sub criteria (from $\mathrm{SSC}_{1}$ to $\mathrm{SSC}_{38}$ ) mentioned towards the intended goal of sustainability performance. The selected important features in Table 1 can be used to explain the approach followed by decision-makers for judgments of alternatives reported in Table 4 as shown below for selected sub-sub criteria by considering three representative examples, one from each sustainability dimension. 


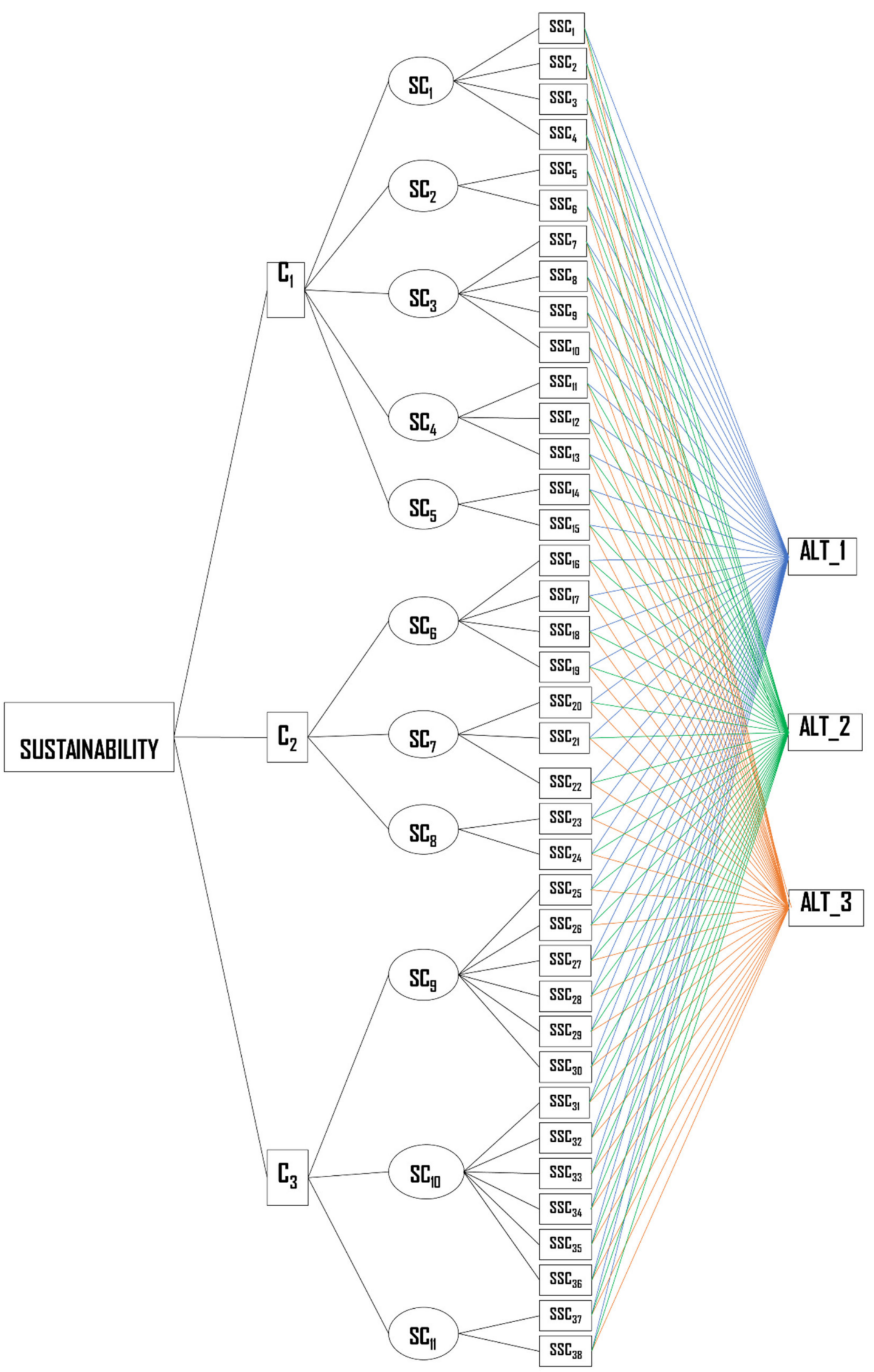

Figure 3. Indicators' tree-proposed four-level hierarchy. 
Table 4. Decision-makers' judgement on existing alternatives.

\begin{tabular}{|c|c|c|c|c|c|c|}
\hline \multirow{2}{*}{$\begin{array}{c}\text { Sub- } \\
\text { Subcriteria }\end{array}$} & \multicolumn{2}{|c|}{$\mathrm{ALT}_{1 /} \mathrm{ALT}_{2}$} & \multicolumn{2}{|c|}{$\mathrm{ALT}_{1} / \mathrm{ALT}_{3}$} & \multicolumn{2}{|c|}{$\mathrm{ALT}_{2} / \mathrm{ALT}_{3}$} \\
\hline & Preference & Evaluation & Preference & Evaluation & Preference & Evaluation \\
\hline $\mathrm{SSC}_{1}$ & $\mathrm{ALT}_{1} / \mathrm{ALT}_{2}$ & 1 & $\mathrm{ALT}_{3}$ & $1 / 5$ & $\mathrm{ALT}_{3}$ & $1 / 3$ \\
\hline $\mathrm{SSC}_{2}$ & $\mathrm{ALT}_{1}$ & 6 & $\mathrm{ALT}_{1}$ & 3 & $\mathrm{ALT}_{3}$ & $1 / 4$ \\
\hline $\mathrm{SSC}_{3}$ & $\mathrm{ALT}_{2}$ & $1 / 3$ & $\mathrm{ALT}_{1}$ & 3 & $\mathrm{ALT}_{2}$ & 5 \\
\hline $\mathrm{SSC}_{4}$ & $\mathrm{ALT}_{2}$ & $1 / 3$ & $\mathrm{ALT}_{1}$ & 2 & $\mathrm{ALT}_{2}$ & 3 \\
\hline $\mathrm{SSC}_{5}$ & $\mathrm{ALT}_{1} / \mathrm{ALT}_{2}$ & 1 & $\mathrm{ALT}_{1}$ & 9 & $\mathrm{ALT}_{2}$ & 7 \\
\hline $\mathrm{SSC}_{6}$ & $\mathrm{ALT}_{2}$ & $1 / 4$ & $\mathrm{ALT}_{3}$ & $1 / 3$ & $\mathrm{ALT}_{2}$ & 2 \\
\hline $\mathrm{SSC}_{7}$ & $\mathrm{ALT}_{1}$ & 7 & $\mathrm{ALT}_{1}$ & 5 & $\mathrm{ALT}_{3}$ & $1 / 2$ \\
\hline $\mathrm{SSC}_{8}$ & $\mathrm{ALT}_{2}$ & $1 / 7$ & $\mathrm{ALT}_{3}$ & $1 / 2$ & $\mathrm{ALT}_{2}$ & 6 \\
\hline $\mathrm{SSC}_{9}$ & $\mathrm{ALT}_{2}$ & $1 / 7$ & $\mathrm{ALT}_{3}$ & $1 / 2$ & $\mathrm{ALT}_{2}$ & 6 \\
\hline $\mathrm{SSC}_{10}$ & $\mathrm{ALT}_{2}$ & $1 / 6$ & $\mathrm{ALT}_{1} / \mathrm{ALT}_{3}$ & 1 & $\mathrm{ALT}_{2}$ & 4 \\
\hline $\mathrm{SSC}_{11}$ & $\mathrm{ALT}_{1}$ & 6 & $\mathrm{ALT}_{1}$ & 3 & $\mathrm{ALT}_{3}$ & $1 / 4$ \\
\hline $\mathrm{SSC}_{12}$ & $\mathrm{ALT}_{1}$ & 7 & $\mathrm{ALT}_{1}$ & 3 & $\mathrm{ALT}_{3}$ & $1 / 4$ \\
\hline $\mathrm{SSC}_{13}$ & $\mathrm{ALT}_{1}$ & 8 & $\mathrm{ALT}_{1}$ & 3 & $\mathrm{ALT}_{3}$ & $1 / 5$ \\
\hline $\mathrm{SSC}_{14}$ & $\mathrm{ALT}_{1}$ & 7 & $\mathrm{ALT}_{1}$ & 4 & $\mathrm{ALT}_{3}$ & $1 / 3$ \\
\hline $\mathrm{SSC}_{15}$ & $\mathrm{ALT}_{2}$ & $1 / 7$ & $\mathrm{ALT}_{3}$ & $1 / 4$ & $\mathrm{ALT}_{2}$ & 3 \\
\hline $\mathrm{SSC}_{16}$ & $\mathrm{ALT}_{1}$ & 8 & $\mathrm{ALT}_{1}$ & 3 & $\mathrm{ALT}_{3}$ & $1 / 5$ \\
\hline $\mathrm{SSC}_{17}$ & $\mathrm{ALT}_{1}$ & 8 & $\mathrm{ALT}_{1}$ & 3 & $\mathrm{ALT}_{3}$ & $1 / 5$ \\
\hline $\mathrm{SSC}_{18}$ & $\mathrm{ALT}_{2}$ & $1 / 9$ & $\mathrm{ALT}_{3}$ & $1 / 6$ & $\mathrm{ALT}_{2}$ & 3 \\
\hline $\mathrm{SSC}_{19}$ & $\mathrm{ALT}_{2}$ & $1 / 6$ & $\mathrm{ALT}_{3}$ & $1 / 2$ & $\mathrm{ALT}_{2}$ & 4 \\
\hline $\mathrm{SSC}_{20}$ & $\mathrm{ALT}_{1}$ & 6 & $\mathrm{ALT}_{1}$ & 2 & $\mathrm{ALT}_{3}$ & $1 / 6$ \\
\hline $\mathrm{SSC}_{21}$ & $\mathrm{ALT}_{2}$ & $1 / 4$ & $\mathrm{ALT}_{3}$ & $1 / 2$ & $\mathrm{ALT}_{2}$ & 4 \\
\hline $\mathrm{SSC}_{22}$ & $\mathrm{ALT}_{2}$ & $1 / 6$ & $\mathrm{ALT}_{3}$ & $1 / 2$ & $\mathrm{ALT}_{2}$ & 6 \\
\hline $\mathrm{SSC}_{23}$ & $\mathrm{ALT}_{1}$ & 8 & $\mathrm{ALT}_{1}$ & 4 & $\mathrm{ALT}_{3}$ & $1 / 3$ \\
\hline $\mathrm{SSC}_{24}$ & $\mathrm{ALT}_{2}$ & $1 / 5$ & $\mathrm{ALT}_{3}$ & $1 / 2$ & $\mathrm{ALT}_{2}$ & 5 \\
\hline $\mathrm{SSC}_{25}$ & $\mathrm{ALT}_{1}$ & 8 & $\mathrm{ALT}_{1}$ & 3 & $\mathrm{ALT}_{3}$ & $1 / 5$ \\
\hline $\mathrm{SSC}_{26}$ & $\mathrm{ALT}_{1}$ & 7 & $\mathrm{ALT}_{1}$ & 4 & $\mathrm{ALT}_{3}$ & $1 / 3$ \\
\hline $\mathrm{SSC}_{27}$ & $\mathrm{ALT}_{1}$ & 6 & $\mathrm{ALT}_{1}$ & 4 & $\mathrm{ALT}_{3}$ & $1 / 3$ \\
\hline $\mathrm{SSC}_{28}$ & $\mathrm{ALT}_{1}$ & 5 & $\mathrm{ALT}_{1}$ & 2 & $\mathrm{ALT}_{3}$ & $1 / 5$ \\
\hline $\mathrm{SSC}_{29}$ & $\mathrm{ALT}_{1}$ & 6 & $\mathrm{ALT}_{1}$ & 4 & $\mathrm{ALT}_{3}$ & $1 / 3$ \\
\hline $\mathrm{SSC}_{30}$ & $\mathrm{ALT}_{1}$ & 6 & $\mathrm{ALT}_{1}$ & 4 & $\mathrm{ALT}_{3}$ & $1 / 3$ \\
\hline $\mathrm{SSC}_{31}$ & $\mathrm{ALT}_{1}$ & 5 & $\mathrm{ALT}_{1}$ & 3 & $\mathrm{ALT}_{3}$ & $1 / 3$ \\
\hline $\mathrm{SSC}_{32}$ & $\mathrm{ALT}_{1}$ & 3 & $\mathrm{ALT}_{1}$ & 6 & $\mathrm{ALT}_{2}$ & 3 \\
\hline $\mathrm{SSC}_{33}$ & $\mathrm{ALT}_{1}$ & 5 & $\mathrm{ALT}_{1}$ & 3 & $\mathrm{ALT}_{3}$ & $1 / 3$ \\
\hline $\mathrm{SSC}_{34}$ & $\mathrm{ALT}_{1}$ & 5 & $\mathrm{ALT}_{3}$ & $1 / 2$ & $\mathrm{ALT}_{3}$ & $1 / 5$ \\
\hline $\mathrm{SSC}_{35}$ & $\mathrm{ALT}_{1}$ & 4 & $\mathrm{ALT}_{1}$ & 4 & $\mathrm{ALT}_{2}$ & 2 \\
\hline $\mathrm{SSC}_{36}$ & $\mathrm{ALT}_{1}$ & 4 & $\mathrm{ALT}_{1}$ & 2 & $\mathrm{ALT}_{3}$ & $1 / 4$ \\
\hline $\mathrm{SSC}_{37}$ & $\mathrm{ALT}_{2}$ & $1 / 4$ & $\mathrm{ALT}_{3}$ & $1 / 2$ & $\mathrm{ALT}_{2}$ & 4 \\
\hline $\mathrm{SSC}_{38}$ & $\mathrm{ALT}_{1}$ & 4 & $\mathrm{ALT}_{1}$ & 6 & $\mathrm{ALT}_{2}$ & 3 \\
\hline
\end{tabular}

1. Material consumption $\left(\mathrm{SSC}_{1}\right)$ - As mentioned in Section 3.2.1, the material consumption is approximated from the total weight of Faceshield brackets. Thus, for $\mathrm{SSC}_{1}$, decision-makers consider equal judgment for $\mathrm{ALT}_{1}$ and $\mathrm{ALT}_{2}$ since the weights of Faceshield manufactured by the two processes are $36 \mathrm{~g}$ and $32 \mathrm{~g}$ and did not show a big variation (intensity of importance falls within the range of equal importance). However, as compared to these two processes, the Faceshield bracket manufactured by $\mathrm{ALT}_{3}$ weighs $13 \mathrm{~g}$, which is the least weight, and for $\mathrm{SSC}_{1}$, it is the preferred alternative for this sub-sub criteria than the two where the importance level from the comparison table shown in Table 3 is strong importance for $\mathrm{ALT}_{1}$ and moderate importance for ALT3.

2. Economic cost $\left(\mathrm{SSC}_{17}\right)$-The judgment made on economic cost is based on the cost of each machine used for the three alternatives. As compared to $\mathrm{ALT}_{1}$, the machine costs for $\mathrm{ALT}_{3}$ are lower and even very much lower for $\mathrm{ALT}_{2}$. As per the information gathered, $\mathrm{ALT}_{2}$ costs about EUR 3000 and $\mathrm{ALT}_{3}$ costs about EUR 15,000. Though this does not mean there are equivalent production rates and economic value of the Faceshield bracket, the initial economic cost is important for users. Therefore, based 
on this understanding, $\mathrm{ALT}_{1}$ is given a higher value than $\mathrm{ALT}_{2}$ and $\mathrm{ALT}_{3}$ with an intensity of importance 8 and 3 respectively, whereas $\mathrm{ALT}_{3}$ is given a value of strong importance (intensity of 5 ).

3. Skill management $\left(\mathrm{SSC}_{31}\right)$-Based on Section 3.4.3, average hours of training and education for specific skill, knowledge, or competence needed $\left(\mathrm{SSC}_{31}\right)$ varies with the type and hours required depending on the type of manufacturing process. Moreover, Table 1 represents that training is more highly needed for $\mathrm{ALT}_{1}$ than $\mathrm{ALT}_{3}$ and $\mathrm{ALT}_{2}$, respectively. The training needed for $\mathrm{ALT}_{2}$ is not that relevant. Thus, based on this information, decision-makers preferred $\mathrm{ALT}_{1}$ with strong importance concerning $\mathrm{ALT}_{2}$ and moderate importance with $\mathrm{ALT}_{3}$. Moreover, $\mathrm{ALT}_{3}$ was preferred over $\mathrm{ALT}_{2}$ with moderate importance, as per Table 3 .

\subsubsection{Criteria Comparison-Criteria and Subcriteria}

AHP analysis was performed through step-by-step analysis of scores of each criterion, subcriteria, and sub-sub criteria for all four levels. The mathematical formulation is generally presented and adjusted whenever the level changes: a square matrix (A) of size $n$ for each level and corresponding normalized matrix, $A_{\text {norm }}$, and criteria weight vector $W i$. The elements of the matrix are represented by $a_{i j}$, corresponding to $i^{\text {th }}$ row and $j^{\text {th }}$ column as summarized in Table 5 . Similarly, for consistency verification, the average consistency index proposed by [47] is utilized as reported in Table 6 .

Table 5. Matrices and equations.

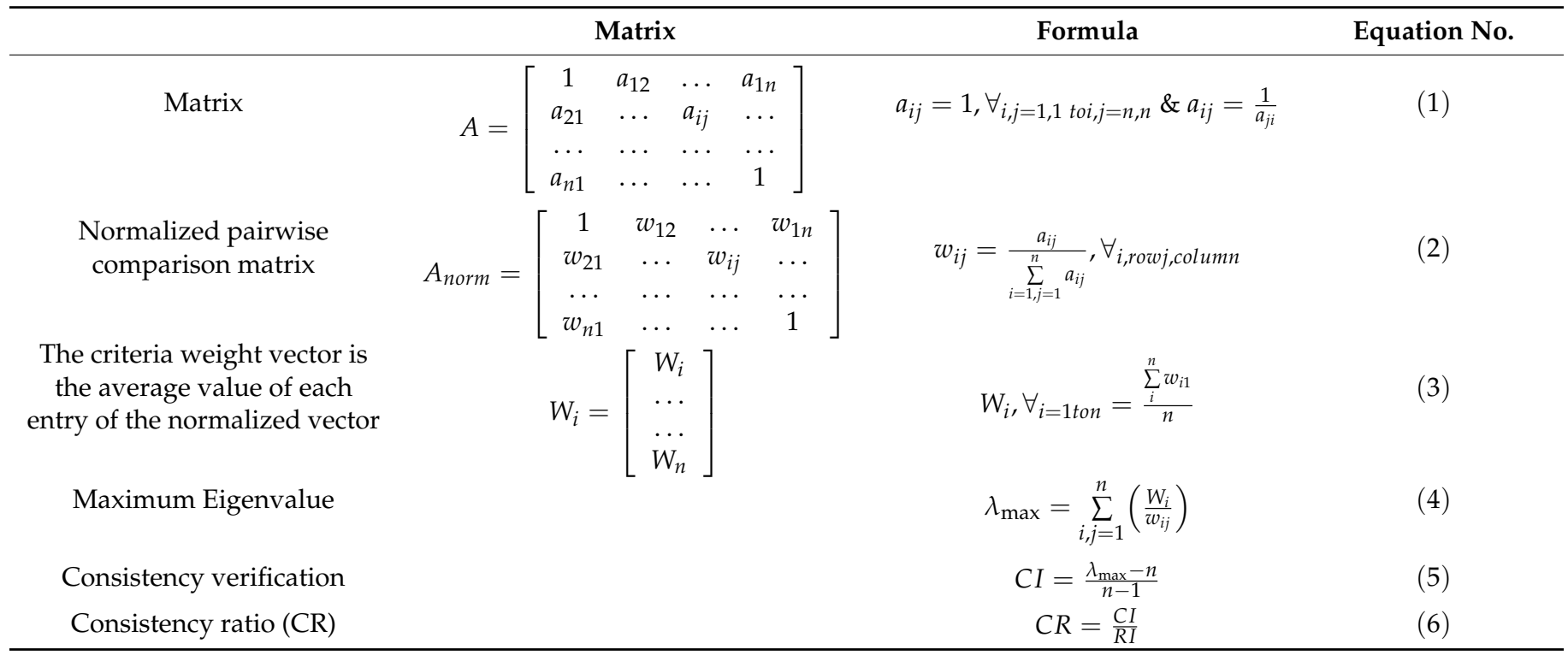

Table 6. Average consistency index ([47]).

\begin{tabular}{ccccccccccc}
\hline $\boldsymbol{n}$ & $\mathbf{1}$ & $\mathbf{2}$ & $\mathbf{3}$ & $\mathbf{4}$ & $\mathbf{5}$ & $\mathbf{6}$ & $\mathbf{7}$ & $\mathbf{8}$ & $\mathbf{9}$ & $\mathbf{1 0}$ \\
\hline $\mathrm{RI}$ & 0.00 & 0.00 & 0.52 & 0.89 & 1.11 & 1.25 & 1.35 & 1.40 & 1.45 & 1.49 \\
\hline
\end{tabular}

Tables 7-9 report performance comparison values for each subcriteria and sub-sub criteria for the three dimensions of sustainability. Comparison tables were generated based on decision-makers' judgments based on the proposed hierarchy. Performance value calculations for criteria and subcriteria, calculations of aggregations for criteria and sub-sub criteria, as well as final aggregation of the 38 sub-sub criteria with the three alternatives were done to evaluate overall sustainability performance as reported in Section 4 . Results are reported as the best alternatives of each criterion and finally as overall sustainability performance. 
Table 7. Criteria comparison table for the goal (sustainability).

\begin{tabular}{cccc}
\hline Goal & Comparison & Preference & Evaluation \\
\hline \multirow{3}{*}{ Sustainability } & $C_{1} / C_{2}$ & $C_{2}$ & $1 / 2$ \\
& $C_{1} / C_{3}$ & $C_{1} / C_{3}$ & 1 \\
& $C_{2} / C_{3}$ & $C_{2}$ & 2 \\
\hline
\end{tabular}

Table 8. Subcriteria comparison table for the three dimensions.

\begin{tabular}{|c|c|c|c|}
\hline Goal & Comparison & Preference & Evaluation \\
\hline \multirow{11}{*}{$\mathrm{C}_{1}$} & $\mathrm{SC}_{1} / \mathrm{SC}_{2}$ & $\mathrm{SC}_{1} / \mathrm{SC}_{2}$ & 1 \\
\hline & $\mathrm{SC}_{1} / \mathrm{SC}_{3}$ & $\mathrm{SC}_{1}$ & 8 \\
\hline & $\mathrm{SC}_{1} / \mathrm{SC}_{4}$ & $\mathrm{SC}_{1}$ & 8 \\
\hline & $\mathrm{SC}_{1} / \mathrm{SC}_{5}$ & $\mathrm{SC}_{1}$ & 4 \\
\hline & $\mathrm{SC}_{2} / \mathrm{SC}_{3}$ & $\mathrm{SC}_{2}$ & 8 \\
\hline & $\mathrm{SC}_{2} / \mathrm{SC}_{4}$ & $\mathrm{SC}_{2}$ & 8 \\
\hline & $\mathrm{SC}_{2} / \mathrm{SC}_{5}$ & $\mathrm{SC}_{2}$ & 2 \\
\hline & $\mathrm{SC}_{3} / \mathrm{SC}_{4}$ & $\mathrm{SC}_{3} / \mathrm{SC}_{4}$ & 1 \\
\hline & $\mathrm{SC}_{3} / \mathrm{SC}_{5}$ & $\mathrm{SC}_{5}$ & $1 / 7$ \\
\hline & $\mathrm{SC}_{4} / \mathrm{SC}_{5}$ & $\mathrm{SC}_{5}$ & $1 / 7$ \\
\hline & $\mathrm{SC}_{6} / \mathrm{SC}_{7}$ & $\mathrm{SC}_{6}$ & 7 \\
\hline \multirow[t]{6}{*}{$\mathrm{C}_{2}$} & $\mathrm{SC}_{6} / \mathrm{SC}_{8}$ & $\mathrm{SC}_{6}$ & 4 \\
\hline & $\mathrm{SC}_{7} / \mathrm{SC}_{8}$ & $\mathrm{SC}_{8}$ & $1 / 3$ \\
\hline & $\mathrm{SC}_{9} / \mathrm{SC}_{10}$ & $\mathrm{SC}_{9} / \mathrm{SC}_{10}$ & 1 \\
\hline & $\mathrm{SC}_{9} / \mathrm{SC}_{11}$ & $\mathrm{SC}_{9}$ & 3 \\
\hline & $\mathrm{SC}_{9} / \mathrm{SC}_{12}$ & $\mathrm{SC}_{9}$ & 5 \\
\hline & $\mathrm{SC}_{9} / \mathrm{SC}_{13}$ & $\mathrm{SC}_{9}$ & 5 \\
\hline \multirow{6}{*}{$\mathrm{C}_{3}$} & $\mathrm{SC}_{10} / \mathrm{SC}_{11}$ & $\mathrm{SC}_{10}$ & 3 \\
\hline & $\mathrm{SC}_{10} / \mathrm{SC}_{12}$ & $\mathrm{SC}_{10}$ & 6 \\
\hline & $\mathrm{SC}_{10} / \mathrm{SC}_{13}$ & $\mathrm{SC}_{10}$ & 6 \\
\hline & $\mathrm{SC}_{11} / \mathrm{SC}_{12}$ & $\mathrm{SC}_{11}$ & 5 \\
\hline & $\mathrm{SC}_{11} / \mathrm{SC}_{13}$ & $\mathrm{SC}_{11}$ & 3 \\
\hline & $\mathrm{SC}_{12} / \mathrm{SC}_{13}$ & $\mathrm{SC}_{12}$ & 3 \\
\hline
\end{tabular}

Table 9. Sub-sub criteria comparison table for subcriteria.

\begin{tabular}{cccc}
\hline Subcriteria & Comparison & Preference & Evaluation \\
\hline & $\mathrm{SSC}_{1} / \mathrm{SSC}_{2}$ & $\mathrm{SSC}_{1}$ & 3 \\
& $\mathrm{SSC}_{1} / \mathrm{SSC}_{3}$ & $\mathrm{SSC}_{1}$ & 3 \\
$\mathrm{SSC}_{1} / \mathrm{SSC}_{4}$ & $\mathrm{SSC}_{1}$ & 2 \\
$\mathrm{SC}_{1}$ & $\mathrm{SSC}_{2} / \mathrm{SC}_{3}$ & $\mathrm{SSC}_{2}$ & 3 \\
& $\mathrm{SSC}_{2} / \mathrm{SSC}_{4}$ & $\mathrm{SSC}_{4}$ & $1 / 3$ \\
& $\mathrm{SSC}_{3} / \mathrm{SSC}_{4}$ & $\mathrm{SSC}_{4}$ & $1 / 4$ \\
$\mathrm{SC}_{2}$ & $\mathrm{SSC}_{5} / \mathrm{SSC}_{6}$ & $\mathrm{SSC}_{5}$ & 2 \\
& $\mathrm{SSC}_{7} / \mathrm{SSC}_{8}$ & $\mathrm{SSC}_{7}$ & 3 \\
& $\mathrm{SSC}_{7} / \mathrm{SSC}_{9}$ & $\mathrm{SSC}_{7}$ & 5 \\
& $\mathrm{SSC}_{7} / \mathrm{SSC}_{10}$ & $\mathrm{SSC}_{10}$ & $1 / 4$ \\
$\mathrm{SC}_{3}$ & $\mathrm{SSC}_{8} / \mathrm{SSC}_{9}$ & $\mathrm{SSC}_{8}$ & 3 \\
& $\mathrm{SSC}_{3} / \mathrm{SSC}_{10}$ & $\mathrm{SSC}_{10}$ & $1 / 6$ \\
& $\mathrm{SSC}_{10} / \mathrm{SSC}_{10}$ & $\mathrm{SSC}_{10}$ & $1 / 8$ \\
& $\mathrm{SSC}_{11} / \mathrm{SSC}_{12}$ & $\mathrm{SSC}_{12}$ & $1 / 3$ \\
& $\mathrm{SSC}_{11} / \mathrm{SSC}_{13}$ & $\mathrm{SSC}_{13}$ & $1 / 3$ \\
$\mathrm{SC}_{4}$ & $\mathrm{SSC}_{12} / \mathrm{SSC}_{13}$ & $\mathrm{SSC}_{13}$ & $1 / 5$ \\
& $\mathrm{SSC}_{14} / \mathrm{SSC}_{15}$ & $\mathrm{SSC}_{15}$ & \\
$\mathrm{SC}_{5}$ & & &
\end{tabular}


Table 9. Cont.

\begin{tabular}{|c|c|c|c|}
\hline Subcriteria & Comparison & Preference & Evaluation \\
\hline \multirow{6}{*}{$\mathrm{SC}_{6}$} & $\mathrm{SSC}_{16} / \mathrm{SSC}_{17}$ & $\mathrm{SSC}_{17}$ & $1 / 2$ \\
\hline & $\mathrm{SSC}_{16} / \mathrm{SSC}_{18}$ & $\mathrm{SSC}_{16}$ & 2 \\
\hline & $\mathrm{SSC}_{16} / \mathrm{SSC}_{19}$ & $\mathrm{SSC}_{19}$ & $1 / 3$ \\
\hline & $\mathrm{SSC}_{17} / \mathrm{SSC}_{18}$ & $\mathrm{SSC}_{17}$ & 2 \\
\hline & $\mathrm{SSC}_{17} / \mathrm{SSC}_{19}$ & $\mathrm{SSC}_{19}$ & $1 / 2$ \\
\hline & $\mathrm{SSC}_{18} / \mathrm{SSC}_{19}$ & $\mathrm{SSC}_{19}$ & $1 / 4$ \\
\hline \multirow{3}{*}{$\mathrm{SC}_{7}$} & $\mathrm{SSC}_{20} / \mathrm{SSC}_{21}$ & $\mathrm{SSC}_{20}$ & 4 \\
\hline & $\mathrm{SSC}_{20} / \mathrm{SSC}_{22}$ & $\mathrm{SSC}_{20}$ & 2 \\
\hline & $\mathrm{SSC}_{21} / \mathrm{SSC}_{22}$ & $\mathrm{SSC}_{22}$ & $1 / 4$ \\
\hline \multirow[t]{2}{*}{$\mathrm{SC}_{8}$} & $\mathrm{SSC}_{23} / \mathrm{SSC}_{24}$ & $\mathrm{SSC}_{23}$ & 3 \\
\hline & $\mathrm{SSC}_{25} / \mathrm{SSC}_{26}$ & $\mathrm{SSC}_{26}$ & $1 / 2$ \\
\hline \multirow{5}{*}{$\mathrm{SC}_{9}$} & $\mathrm{SSC}_{25} / \mathrm{SSC}_{27}$ & $\mathrm{SSC}_{27}$ & $1 / 4$ \\
\hline & $\mathrm{SSC}_{25} / \mathrm{SSC}_{28}$ & $\mathrm{SSC}_{25}$ & 2 \\
\hline & $\mathrm{SSC}_{26} / \mathrm{SSC}_{27}$ & $\mathrm{SSC}_{27}$ & $1 / 2$ \\
\hline & $\mathrm{SSC}_{26} / \mathrm{SSC}_{28}$ & $\mathrm{SSC}_{26}$ & 4 \\
\hline & $\mathrm{SSC}_{27} / \mathrm{SSC}_{28}$ & $\mathrm{SSC}_{27}$ & 7 \\
\hline \multirow[t]{2}{*}{$\mathrm{SC}_{10}$} & $\mathrm{SSC}_{29} / \mathrm{SSC}_{30}$ & $\mathrm{SSC}_{29}$ & 3 \\
\hline & $\mathrm{SSC}_{31} / \mathrm{SSC}_{32}$ & $\mathrm{SSC}_{31}$ & 3 \\
\hline \multirow[t]{3}{*}{$\mathrm{SC}_{11}$} & $\mathrm{SSC}_{31} / \mathrm{SSC}_{33}$ & $\mathrm{SSC}_{31}$ & 2 \\
\hline & $\mathrm{SSC}_{32} / \mathrm{SSC}_{33}$ & $\mathrm{SSC}_{33}$ & $1 / 2$ \\
\hline & $\mathrm{SSC}_{34} / \mathrm{SSC}_{35}$ & $\mathrm{SSC}_{34}$ & 3 \\
\hline \multirow[t]{2}{*}{$\mathrm{SC}_{12}$} & $\mathrm{SSC}_{34} / \mathrm{SSC}_{36}$ & $\mathrm{SSC}_{36}$ & $1 / 2$ \\
\hline & $\mathrm{SSC}_{35} / \mathrm{SSC}_{36}$ & $\mathrm{SSC}_{36}$ & $1 / 3$ \\
\hline $\mathrm{SC}_{13}$ & $\mathrm{SSC}_{37} / \mathrm{SSC}_{38}$ & $\mathrm{SSC}_{37}$ & 2 \\
\hline
\end{tabular}

\section{Results and Discussion}

For this study, three alternatives, injection molding $\left(\mathrm{ALT}_{1}\right), 3 \mathrm{D}$ printing $\left(\mathrm{ALT}_{2}\right)$ and laser cutting $\left(\mathrm{ALT}_{3}\right)$ were evaluated for sustainability performance in the manufacturing of the Faceshield bracket. Sustainability evaluation was conducted based on the three dimensions, environment, economic and social, as criteria with corresponding subcriteria and sub-sub criteria. The first task was to identify criteria and subcriteria for each dimension of sustainability. Then, based on the identified list of criteria, subcriteria, and alternatives, a decision tree was set up to break down the problem into different levels so that analysis on each comparison judgment matrix and calculation of aggregated criteria, subcriteria, sub-sub criteria, and alternatives is simplified. The judgment table was set up after examining the evaluations of two experts. Through each judgment, a consistency verification was made by determining consistency ratios for each judgment matrix. The final aggregation results of the AHP analysis are reported in Figures 6-10.

\subsection{Best Alternatives of the Environment Criteria}

Figure 4 (Table 10) represents environmental performance evaluation results based on the five subcriteria and the fifteen sub-sub criteria. The results show the following outcomes.

- Material-The first score goes to laser cutting (0.038), which shows better performance, and the largest contribution came from $\mathrm{SSC}_{1}$ (material consumption). Indeed, the use of thin plates and the optimal arrangement of the parts on them greatly reduce material consumption. The second score is for 3D printing (0.033), with major contributions coming from material value recovery $\left(\mathrm{SSC}_{4}\right)$, and finally, the third score goes to injection molding (0.027), where the major contributor is material efficiency $\left(\mathrm{SSC}_{2}\right)$.

- Energy-3D printing (0.041) ranked first, where the major contribution comes from energy consumption $\left(\mathrm{SSC}_{5}\right)$. Injection molding (0.031) ranked second, where the major contribution comes from $\mathrm{SSC}_{5}$, and laser cutting (0.012) ranked third, where the major contribution comes from $\mathrm{SSC}_{6}$ (renewables). Energy is the most differentiating criterion, as the consumption of individual machines is low. 
- Emission, effluent, and waste-3D printing (0.006) showed better performance and the largest contributor is $\mathrm{SSC}_{10}$ (waste). Injection molding shows the second-best performance (0.003), where the major contribution comes from $\mathrm{SSC}_{7}$ (GHG emission), and third performance is recorded from laser cutting $(0.018)$, where major contribution comes from $\mathrm{SSC}_{10}$ (waste).

- Conformance-Injection molding (0.006) shows better performance where the largest contributor is $\mathrm{SSC}_{13}$ (Expenditure), laser cutting (0.003) shows the second-best performance where the largest contributor is $\mathrm{SSC}_{13}$, and $3 \mathrm{D}$ printing $(0.001)$ shows the third-best performance where the largest contribution is $\mathrm{SSC}_{13}$.

- Transportation-3D printing (0.035) shows better performance, and the largest contributor is $\mathrm{SSC}_{15}$ (transportation strategy). The second-best performance is from injection molding (0.027) and the third-best from laser cutting (0.013), where the major contributor for both cases is $\mathrm{SSC}_{15}$. 3D printing allows local production that reduces transportation, unlike injection modeling.

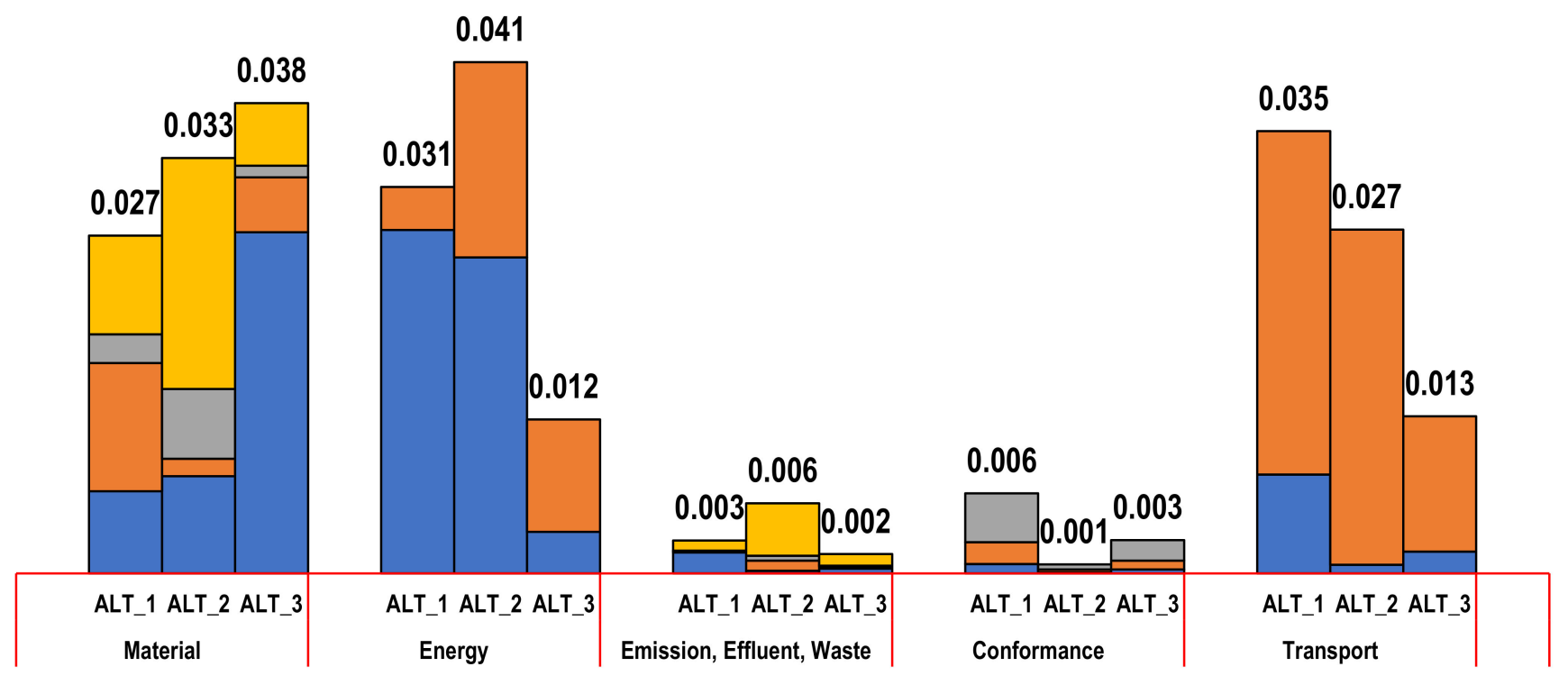

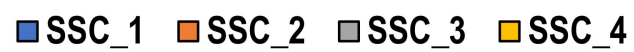

Figure 4. Environmental performance.

Table 10. Key (Figure 4).

\begin{tabular}{|c|c|c|c|c|c|c|}
\hline \multirow{5}{*}{ Key } & & $\begin{array}{l}\text { Material, } \\
\mathrm{SC}_{1}\end{array}$ & $\begin{array}{l}\text { Energy, } \\
\mathrm{SC}_{2}\end{array}$ & $\begin{array}{c}\text { Emission, Effluent, } \\
\text { Waste, } \mathrm{SC}_{3}\end{array}$ & $\begin{array}{c}\text { Conformance, } \\
\mathrm{SC}_{4}\end{array}$ & $\begin{array}{l}\text { Transport, } \\
\text { SC }_{5}\end{array}$ \\
\hline & SSC_1 & $\mathrm{SSC}_{1}$ & $\mathrm{SSC}_{5}$ & $\mathrm{SSC}_{7}$ & $\mathrm{SSC}_{11}$ & $\mathrm{SSC}_{14}$ \\
\hline & SSC_2 & $\mathrm{SSC}_{2}$ & $\mathrm{SSC}_{6}$ & $\mathrm{SSC}_{8}$ & $\mathrm{SSC}_{12}$ & $\mathrm{SSC}_{15}$ \\
\hline & SSC_3 & $\mathrm{SSC}_{3}$ & & $\mathrm{SSC}_{9}$ & $\mathrm{SSC}_{13}$ & \\
\hline & SSC_4 & $\mathrm{SSC}_{4}$ & & $\mathrm{SSC}_{10}$ & & \\
\hline
\end{tabular}

\subsection{Best Alternatives of the Economic Criteria}

Figure 5 (Table 11) represents economic performance evaluation results based on the three subcriteria and the nine sub-sub criteria. The results show the following outcomes.

- For economic viability-3D printing (0.151) shows better performance, and the largest contribution came from $\mathrm{SSC}_{19}$ (benefit plan). Injection molding (0.117) shows the second-best performance, where the largest contributor is $\mathrm{SSC}_{17}$ (economic cost). The third-best performance goes to laser cutting (0.083), where the largest contribution comes from $\mathrm{SSC}_{19}$ (benefit plan). The economic viability is a cumulative performance measured based on judgments made for economic value, cost, innovation, and benefit plan as described in Section 3.3.1, not just only the economic cost of machines. 
- For marketing presence-3D printing (0.016) shows a slightly better performance, and the largest contributor is related to $\mathrm{SSC}_{22}$ (local community). Injection molding (0.015), where the largest contributor is related to $\mathrm{SSC}_{20}$ (wages), and laser cutting (0.012), where the largest contribution comes from to $\mathrm{SSC}_{20}$, showed the second- and third-best performance.

- For indirect economic impact-Injection molding (0.060) shows better performance, and the largest contributor is $\mathrm{SSC}_{23}$ (investment); $3 \mathrm{D}$ printing $(0.025)$ is the secondbest alternative, where the largest contribution comes from SSC $_{24}$ (impact knowhow). Laser cutting (0.021) is the third alternative, where the largest contribution comes from $\mathrm{SSC}_{23}$ (investment). The performance by $\mathrm{ALT}_{3}$ is better since the judgments made on the investment are given higher intensity than $\mathrm{ALT}_{2}$ and $\mathrm{ALT}_{3}$. Moreover, as mentioned in Section 3.3.3, injection molding needs an industrial infrastructure of large machine tools which could benefit the public through commercial, in-kind, pro bono, or public good engagement.

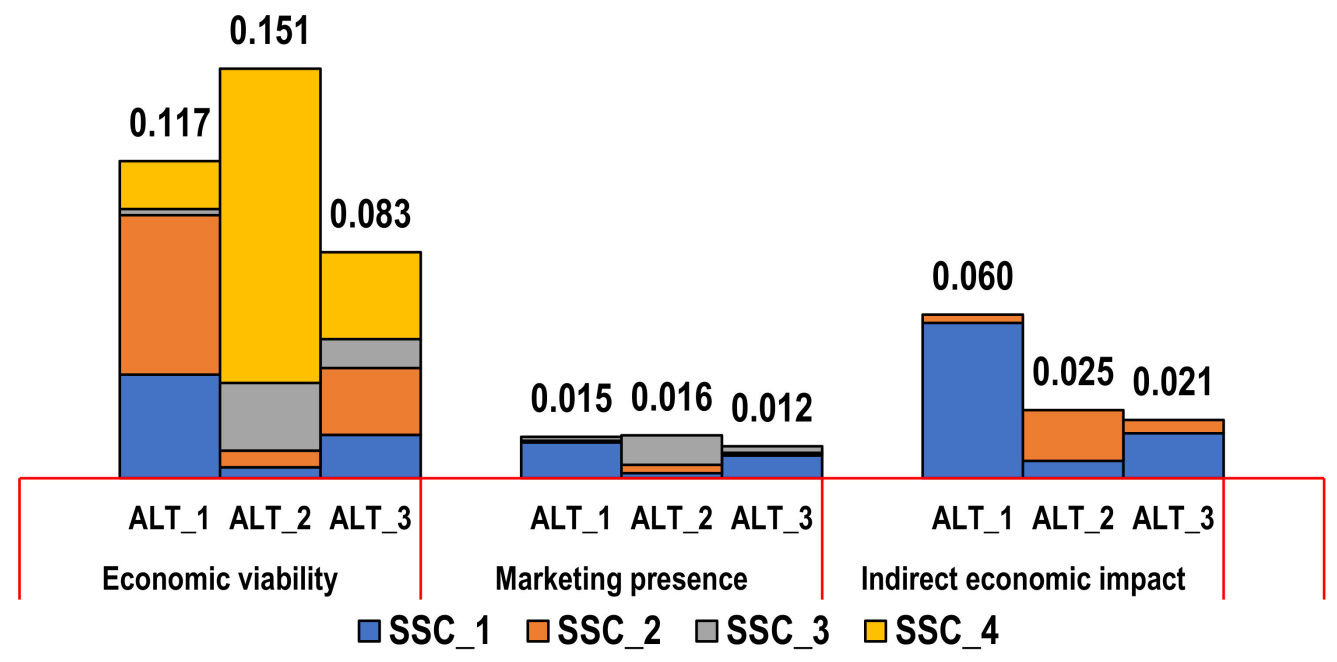

Figure 5. Economic performance.

Table 11. Key (Figure 5).

\begin{tabular}{|c|c|c|c|c|}
\hline \multirow{5}{*}{ Key } & & $\begin{array}{c}\text { Economic } \\
\text { Viability, } \mathrm{SC}_{6}\end{array}$ & $\begin{array}{c}\text { Marketing } \\
\text { Presence, } \mathrm{SC}_{7}\end{array}$ & $\begin{array}{l}\text { Indirect Economic Impact, } \\
\qquad \mathrm{SC}_{8}\end{array}$ \\
\hline & SSC_1 & $\mathrm{SSC}_{16}$ & $\mathrm{SSC}_{20}$ & $\mathrm{SSC}_{23}$ \\
\hline & SSC_2 & $\mathrm{SSC}_{17}$ & $\mathrm{SSC}_{21}$ & $\mathrm{SSC}_{24}$ \\
\hline & SSC_3 & $\mathrm{SSC}_{18}$ & $\mathrm{SSC}_{22}$ & \\
\hline & SSC_4 & $\mathrm{SSC}_{19}$ & & \\
\hline
\end{tabular}

\subsection{Best Alternatives of the Social Criteria}

Figure 6 (Table 12) represents economic performance evaluation results based on the five subcriteria and the fourteen sub-sub criteria. The results show the following outcomes.

- $\quad$ For employment-Injection molding (0.058) shows a better performance, where $\mathrm{SSC}_{27}$ (job security) is the largest contributor. Laser cutting $(0.020)$ is the second-best, where the largest contributor is similarly $\mathrm{SSC}_{27}$, and $3 \mathrm{D}$ printing $(0.007)$ is the third alternative, where the largest contributor is again $\mathrm{SSC}_{27}$. Indeed, injection modeling supposes the creation of a company in a conventional scheme, which tends to secure more jobs than 3D printing.

- For occupational health and safety-Injection molding (0.062) shows better performance, where $\mathrm{SSC}_{29}$ (injury rate) is the largest contributor. Laser cutting (0.020), where the largest contribution is similarly $\mathrm{SSC}_{29}$ is the second-best, and the third-best is $3 \mathrm{D}$ printing $(0.008)$, where the largest contribution is again $\mathrm{SSC}_{29}$. For training 
and education, injection molding (0.027) shows better performance, where $\mathrm{SSC}_{31}$ (training) is the largest contributor; laser cutting $(0.010)$ is the second-best, where the largest contribution is again $\mathrm{SSC}_{31}$, and $3 \mathrm{D}$ printing $(0.058)$ is the third-best alternative where the largest contribution is equally contributed from SSC $_{31}$ (training) and $\mathrm{SSC}_{32}$ (skill management).

- For training and education-Injection molding (0.027) shows better performance, where $\mathrm{SSC}_{31}$ (training) is the largest contributor; laser cutting (0.010) is the secondbest, where the largest contribution is again $\mathrm{SSC}_{31}$, and $3 \mathrm{D}$ printing $(0.005)$ is the third-best alternative, where the largest contribution is equally contributed from $\mathrm{SSC}_{31}$ (training) and $\mathrm{SSC}_{32}$ (skill management).

- For product and service labeling-Injection molding (0.010) shows better performance. where $\mathrm{SSC}_{36}$ (values) is the largest contributor. Laser cutting (0.007) is the second-best alternative, where the largest contributors are customer satisfaction $\left(\mathrm{SSC}_{34}\right)$ and $\mathrm{SSC}_{36}$, and $3 \mathrm{D}$ printing (0.002) is the third alternative with almost equal contribution from $\mathrm{SSC}_{34}$, conformity $\left(\mathrm{SSC}_{35}\right)$ and $\mathrm{SSC}_{36}$.

- $\quad$ For governance-3D printing (0.007) shows better performance, where $\mathrm{SSC}_{37}$ (equity and fairness) is the largest contributor. The second-best is injection molding (0.004), where the largest contribution comes from efficiency $\left(\mathrm{SSC}_{38}\right)$, and the third-best is laser cutting (0.002), where the largest contribution comes from $\mathrm{SSC}_{37}$.

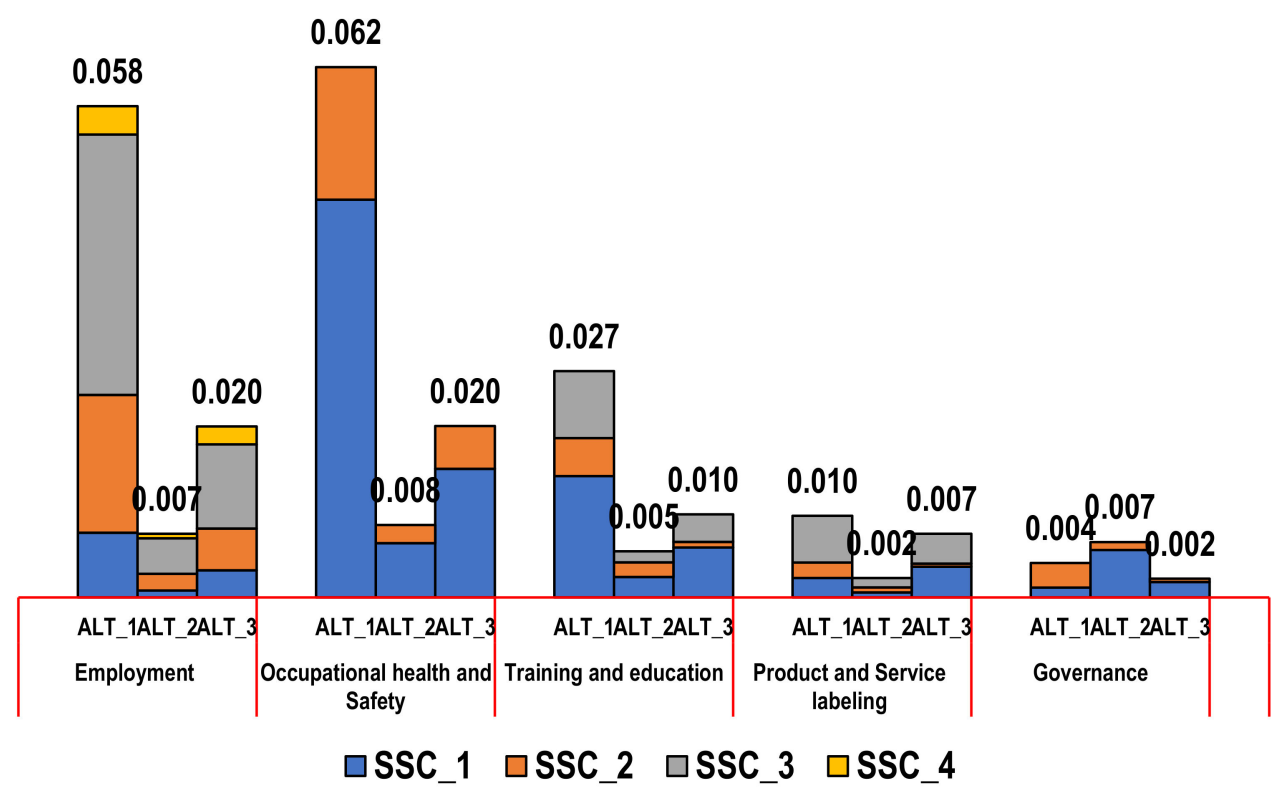

Figure 6. Social performance.

Table 12. Key (Figure 6).

\begin{tabular}{|c|c|c|c|c|c|c|}
\hline \multirow{5}{*}{ Key } & & $\begin{array}{l}\text { Employment, } \\
\text { SC }_{9}\end{array}$ & $\mathrm{OHS}, \mathrm{SC}_{10}$ & $\begin{array}{c}\text { Training and } \\
\text { Education, } \mathrm{SC}_{11}\end{array}$ & $\begin{array}{l}\text { PSS Labeling, } \\
\text { SC }_{12}\end{array}$ & $\begin{array}{l}\text { Governance, } \\
\mathrm{SC}_{13}\end{array}$ \\
\hline & SSC_1 & $\mathrm{SSC}_{25}$ & $\mathrm{SSC}_{29}$ & $\mathrm{SSC}_{31}$ & $\mathrm{SSC}_{34}$ & $\mathrm{SSC}_{37}$ \\
\hline & SSC_2 & $\mathrm{SSC}_{26}$ & $\mathrm{SSC}_{30}$ & $\mathrm{SSC}_{32}$ & $\mathrm{SSC}_{35}$ & $\mathrm{SSC}_{38}$ \\
\hline & SSC_3 & $\mathrm{SSC}_{27}$ & & $\mathrm{SSC}_{33}$ & $\mathrm{SSC}_{36}$ & \\
\hline & SSC_4 & $\mathrm{SSC}_{28}$ & & & & \\
\hline
\end{tabular}

\subsection{Overall Sustainability}

Figure 7 (Table 13) reports overall sustainability performance evaluation results based on the three dimensions. The results show that for environment, 3D printing $(0.108$ or $10.8 \%)>$ injection molding $(0.102$ or $10.2 \%)>$ laser cutting $(0.067$ or $6.7 \%)$. For economic, injection molding $(0.1922$ or $19.22 \%)>3 \mathrm{D}$ printing $(0.1916$ or $19.16 \%)>$ laser cutting $(0.1162$ or $11.62 \%)$, and for social, injection molding $(0.160$ or $16 \%)>$ laser cutting $(0.060$ or $6 \%)>$ 
$3 \mathrm{D}$ printing $(0.030$ or $3 \%)$. These results reveal that for the environment, $3 \mathrm{D}$ printing shows better performance, and the largest contribution came from energy $\left(\mathrm{SC}_{2}=0.041\right.$ or $\left.4.1 \%\right)$. The least contribution came from conformance $\left(\mathrm{SC}_{4}=0.0007\right.$ or $\left.0.07 \%\right)$.

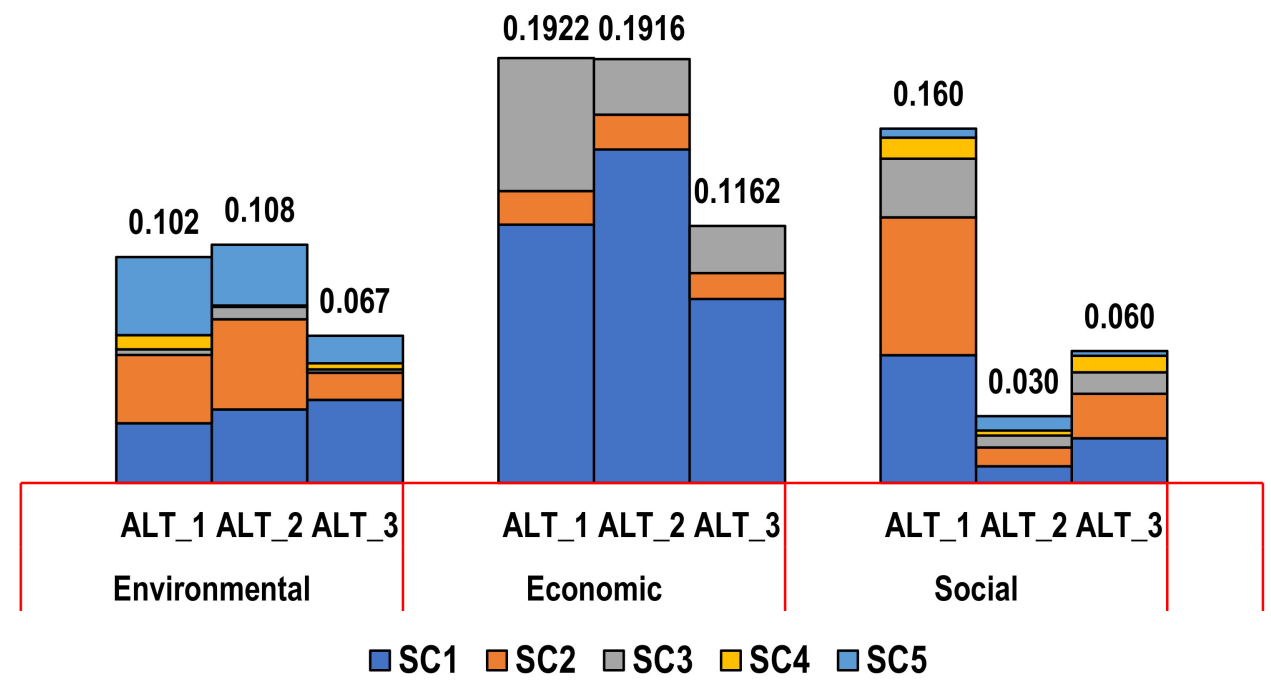

Figure 7. Overall sustainability performance for each sustainability dimension.

Table 13. Key (Figure 7).

\begin{tabular}{ccccc}
\hline & & Environment, $\mathrm{C}_{1}$ & Economic, $\mathrm{C}_{2}$ & $\mathrm{Social}_{1} \mathrm{C}_{3}$ \\
\multirow{5}{*}{ Key } & $\mathrm{SC} 1$ & $\mathrm{SC}_{1}$ & $\mathrm{SC}_{6}$ & $\mathrm{SC}_{9}$ \\
& $\mathrm{SC} 2$ & $\mathrm{SC}_{2}$ & $\mathrm{SC}_{7}$ & $\mathrm{SC}_{10}$ \\
& $\mathrm{SC} 3$ & $\mathrm{SC}_{3}$ & $\mathrm{SC}_{8}$ & $\mathrm{SC}_{11}$ \\
& $\mathrm{SC} 4$ & $\mathrm{SC}_{4}$ & & $\mathrm{SC}_{12}$ \\
& $\mathrm{SC} 5$ & $\mathrm{SC}_{5}$ & & $\mathrm{SC}_{13}$ \\
\hline
\end{tabular}

For the economic dimension, injection molding (slightly larger) and 3D printing show almost equal better performance where the larger contributors are economic viability $\left(\mathrm{SC}_{1}=0.117\right.$ and $\mathrm{SC}_{1}=0.151$, respectively). The least contribution comes from indirect economic impact $\left(\mathrm{SC}_{3}=0.060\right.$ and $\mathrm{SC}_{3}=0.025$, respectively). Finally, for the social dimension, injection molding shows a better performance where $\mathrm{OHS}\left(\mathrm{SC}_{2}=0.062\right)$ is the largest contributor. The least contributor is governance $\left(\mathrm{SC}_{5}=0.004\right)$. Moreover, Figure 8 represents the overall sustainability performance of the three criteria based on the Borda count and sum approach. The ranking using Borda count is injection molding (first), laser cutting (second), 3D printing (third) and the ranking using sum approach is injection molding (first), 3D printing (second), and laser cutting (third).

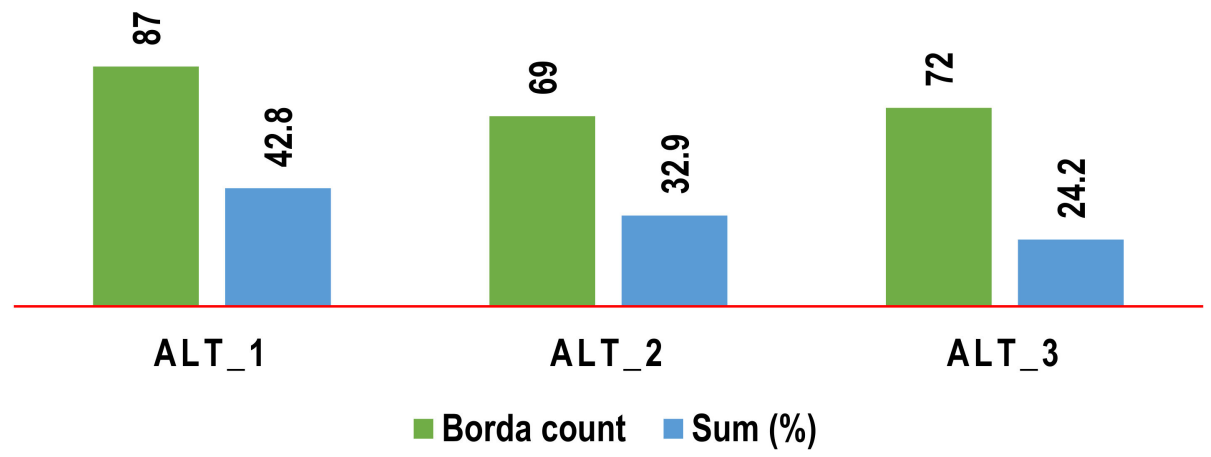

Figure 8. Overall sustainability for the three criteria. 


\section{Conclusions}

In this study, AHP was used to effectively evaluate the sustainability performance of three alternatives: injection molding, 3D printing, and laser cutting used to manufacture three different Faceshield brackets. Based on the analysis, injection molding shows better overall sustainability performance. The total sum approach scores for injection molding, 3D printing, and laser cutting are 42.8, 32.9, and 24.2, and scores based on Borda count methodology are 87,69 , and 72 , respectively.

Similarly, the contribution of each subcriteria and sub-sub criteria were calculated and the sustainability performance of each methodology was analyzed. Based on each dimension, for environment, 3D printing showed better performance (score $=0.108$ ) where the largest contribution came from energy $($ score $=0.041)$. For economic and social dimensions, injection molding had scores of $0.192(19.2 \%)$ and $0.160(16 \%)$, respectively, where largest contributions came from economic viability with a score of $0.117(11.7 \%)$. For the social dimension, where occupational health and safety was the largest contribution, was a score of $0.062(6.2 \%)$.

To make final decisions, the Borda count method was introduced for comparison with the sum approach. For some approaches, the scores of each of the 38 sub-sub criteria were added within each sustainability dimension. This results in scores of 0.428 for injection (ranked first), 0.329 for 3D printing (ranked second), and 0.242 for laser (ranked third). However, since the frequency of the rank of each alternative varies, the introduction of the Borda count method assists a decision. Among the 38 sub-sub criteria, the frequency of better preferences for injection molding, 3D printing, and laser cutting for the first choice was 23,13 , and 2, for the second choice was 3,5 , and 30 and for the third choice was 12,20 and 6, respectively. Thus, scores of Borda count were obtained by adding products of the frequency of the first choice by three and second choice by two, and the third choice by one. This method helps to avoid simple consideration of options that are preferred by the majority and allows considering better performances of other alternatives.

The importance of the findings that result from the analysis is helpful to evaluate the sustainability performance of similar products manufactured through different manufacturing methods, similar to the three methods utilized for this study. For this study, market assessment was not conducted, and some of the social dimensions might have a different performance which can be considered for future works. Future works on different components whether on PPE or related, should consider step-by-step gathering of full relevant information to assist decision-makers' judgment so that the final decision reveals the real performance of the utilized methodology to manufacture the desired part or product.

Author Contributions: Conceptualization, methodology, writing-review and editing, data curation, G.T., S.D. and E.D.; software, formal analysis, writing—original draft preparation, G.T.; validation, resources, visualization, supervision, S.D. and E.D. All authors have read and agreed to the published version of the manuscript.

Funding: A dissertation research grant [No. Dossier - 964433D] by Campus France, the Embassy of France in Addis Ababa and Ethiopian Ministry of Education.

Institutional Review Board Statement: Not applicable.

Informed Consent Statement: Not applicable.

Data Availability Statement: Not applicable.

Acknowledgments: Authors would like to acknowledge Lycée Jean-Zay and Campus Aéronautique Auvergne Rhône Alpes, Fablab at Sigma Clermont for their role in the cooperative development of the product. Furthermore, authors are grateful to Campus France, the Embassy of France in Addis Ababa, and Ethiopian Ministry of Education for offering a dissertation grant during the development of this research.

Conflicts of Interest: The authors have no conflict of interest to declare that are relevant to the content of this article. 


\section{References}

1. Flanagan, S.T.; Ballard, D.H. 3D Printed Face Shields: A Community Response to the COVID-19 Global Pandemic. Acad. Radiol. 2020, 27, 905-906. [CrossRef]

2. Haapala, K.R.; Zhao, F.; Camelio, J.; Sutherland, J.W.; Skerlos, S.J.; Dornfeld, D.A.; Jawahir, I.S.; Clarens, A.F.; Rickli, J.L. A Review of Engineering Research in Sustainable Manufacturing. J. Manuf. Sci. Eng. 2013, 135, 599-619. [CrossRef]

3. Yuan, C.; Zhai, Q.; Dornfeld, D. A Three Dimensional System Approach for Environmentally Sustainable Manufacturing. CIRP Ann. 2012, 61, 39-42. [CrossRef]

4. Saad, M.H.; Nazzal, M.A.; Darras, B.M. A General Framework for Sustainability Assessment of Manufacturing Processes. Ecol. Indic. 2019, 97, 211-224. [CrossRef]

5. Taddese, G.; Durieux, S.; Duc, E. Sustainability Performance Indicators for Additive Manufacturing: A Literature Review Based on Product Life Cycle Studies. Int. J. Adv. Manuf. Technol. 2020, 107, 3109-3134. [CrossRef]

6. Gallo, L.S.; Villas Boas, M.O.C.; Rodrigues, A.C.M.; Melo, F.C.L.; Zanotto, E.D. Transparent Glass-Ceramics for Ballistic Protection: Materials and Challenges. J. Mater. Res. Technol. 2019, 8, 3357-3372. [CrossRef]

7. Garrigou, A.; Laurent, C.; Berthet, A.; Colosio, C.; Jas, N.; Daubas-Letourneux, V.; Jackson Filho, J.-M.; Jouzel, J.-N.; Samuel, O.; Baldi, I.; et al. Critical Review of the Role of PPE in the Prevention of Risks Related to Agricultural Pesticide Use. Saf. Sci. 2020, 123, 104527. [CrossRef]

8. Rewar, S.; Mirdha, D.; Rewar, P. Treatment and Prevention of Pandemic H1N1 Influenza. Ann. Glob. Health 2016, 81, 645. [CrossRef] [PubMed]

9. Rim, K.T.; Koo, K.H.; Park, J.S. Toxicological Evaluations of Rare Earths and Their Health Impacts to Workers: A Literature Review. Saf. Health Work 2013, 4, 12-26. [CrossRef]

10. Sapoval, M.; Gaultier, A.; Del Giudice, C.; Pellerin, O.; Kassis-Chikhani, N.; Lemarteleur, V.; Fouquet, V.; Tapie, L.; Morenton, P.; Tavitian, B.; et al. 3D-Printed Face Protective Shield in Interventional Radiology: Evaluation of an Immediate Solution in the Era of COVID-19 Pandemic. Diagn. Interv. Imaging 2020, 101, 413-415. [CrossRef]

11. Beng, L.G.; Omar, B. Integrating Axiomatic Design Principles into Sustainable Product Development. Int. J. Precis. Eng. Manuf.-Green Technol. 2014, 1, 107-117. [CrossRef]

12. Chatzisideris, M.D.; Espinosa, N.; Laurent, A.; Krebs, F.C. Ecodesign Perspectives of Thin-Film Photovoltaic Technologies: A Review of Life Cycle Assessment Studies. Sol. Energy Mater. Sol. Cells 2016, 156, 2-10. [CrossRef]

13. Deutz, P.; McGuire, M.; Neighbour, G. Eco-Design Practice in the Context of a Structured Design Process: An Interdisciplinary Empirical Study of UK Manufacturers. J. Clean. Prod. 2013, 39, 117-128. [CrossRef]

14. Dufrene, M.; Zwolinski, P.; Brissaud, D. An Engineering Platform to Support a Practical Integrated Eco-Design Methodology. CIRP Ann. 2013, 62, 131-134. [CrossRef]

15. Giffi, A.; Gangula, B.; Illinda, P. 3D-Opportunity-Auto-Industry. Available online: https://www2.deloitte.com/content/dam/ insights/us/articles/additive-manufacturing-3d-opportunity-in-automotive/DUP_707-3D-Opportunity-Auto-Industry_ MASTER.pdf (accessed on 5 March 2018).

16. Maga, D.; Hiebel, M.; Thonemann, N. Life Cycle Assessment of Recycling Options for Polylactic Acid. Resour. Conserv. Recycl. 2019, 149, 86-96. [CrossRef]

17. Bouyssou, D.; Perny, P.; Pirlot, M.; Tsoukiàs, A.; Vincke, P. A Manifesto for the New MCDA Era. J. Multi-Criteria Decis. Anal. 1993, 2, 125-127.

18. Davis, A.Y.; Zhang, Q.; Wong, J.P.S.; Weber, R.J.; Black, M.S. Characterization of Volatile Organic Compound Emissions from Consumer Level Material Extrusion 3D Printers. Build. Environ. 2019, 160, 106209. [CrossRef]

19. Azimi, P.; Zhao, D.; Pouzet, C.; Crain, N.E.; Stephens, B. Emissions of Ultrafine Particles and Volatile Organic Compounds from Commercially Available Desktop Three-Dimensional Printers with Multiple Filaments. Environ. Sci. Technol. 2016, 50, 1260-1268. [CrossRef]

20. Indicators of Sustainable Development: Guidelines and Methodologies, United Nations Publication, 3rd ed.; Vereinte Nationen (Ed.) United Nations: New York, NY, USA, 2007; ISBN 978-92-1-104577-2.

21. Cor, E.; Domingo, L.; Brissaud, D.; Zwolinski, P. A Protocol to Perform Usage Oriented Ecodesign. CIRP Ann. 2014, 63, 169-172. [CrossRef]

22. Badurdeen, F.; Jawahir, I.S. Strategies for Value Creation through Sustainable Manufacturing. Procedia Manuf. 2017, 8, 20-27. [CrossRef]

23. Behrisch, J.; Ramirez, M.; Giurco, D. Representation of Ecodesign Practice: International Comparison of Industrial Design Consultancies. Sustainability 2011, 3, 1778-1791. [CrossRef]

24. Bereketli, I.; Erol Genevois, M. An Integrated QFDE Approach for Identifying Improvement Strategies in Sustainable Product Development. J. Clean. Prod. 2013, 54, 188-198. [CrossRef]

25. Cobut, A.; Beauregard, R.; Blanchet, P. Reducing the Environmental Footprint of Interior Wood Doors in Non-Residential Buildings-Part 2: Ecodesign. J. Clean. Prod. 2015, 109, 247-259. [CrossRef]

26. Chaim, O.; Muschard, B.; Cazarini, E.; Rozenfeld, H. Insertion of Sustainability Performance Indicators in an Industry 4.0 Virtual Learning Environment. Procedia Manuf. 2018, 21, 446-453. [CrossRef]

27. Esty, D.C.; Levy, M.; Srebotnjak, T.; Sherbinin, A. 2005 Environmental Sustainability Index: Benchmarking National Environmental Stewardship; Yale Center for Environmental Law \& Policy: New Heaven, CT, USA, 2005. 
28. Ghobadian, A.; Talavera, I.; Bhattacharya, A.; Kumar, V.; Garza-Reyes, J.A.; O’Regan, N. Examining Legitimatisation of Additive Manufacturing in the Interplay between Innovation, Lean Manufacturing and Sustainability. Int. J. Prod. Econ. 2018, 219, 457-468. [CrossRef]

29. Holm, M. The Future Shop-Floor Operators, Demands, Requirements and Interpretations. J. Manuf. Syst. 2018, 47, 35-42. [CrossRef]

30. Zackrisson, M.; Kurdve, M.; Shahbazi, S.; Wiktorsson, M.; Winroth, M.; Landström, A.; Almström, P.; Andersson, C.; Windmark, C.; Öberg, A.E.; et al. Sustainability Performance Indicators at Shop Floor Level in Large Manufacturing Companies. Procedia CIRP 2017, 61, 457-462. [CrossRef]

31. Borchardt, M.; Wendt, M.H.; Pereira, G.M.; Sellitto, M.A. Redesign of a Component Based on Ecodesign Practices: Environmental Impact and Cost Reduction Achievements. J. Clean. Prod. 2011, 19, 49-57. [CrossRef]

32. Cohen, S.; Bose, S.; Guo, D.; Miller, A.; DeFrancia, K.; Berger, O.; Filiatraut, B.; Loman, M.; Qiu, W.; Zhang, C. The Growth of Sustainability Metrics; Sustainability Metrics White Paper Series, 1; Columbia University Press: New York, NY, USA, 2014.

33. Eastwood, M.D.; Haapala, K.R. A Unit Process Model Based Methodology to Assist Product Sustainability Assessment during Design for Manufacturing. J. Clean. Prod. 2015, 108, 54-64. [CrossRef]

34. Shojaeipour, S. Sustainable Manufacturing Process Planning. Int. J. Adv. Manuf. Technol. 2015, 78, 1347-1360. [CrossRef]

35. BenMena, S. Introduction Aux Méthodes Multicritères d'aide à La Décision. Biotechnol. Agron. Soc. Environ. 2000, 4, 83-93.

36. Alinezhad, A.; Khalili, J. New Methods and Applications in Multiple Attribute Decision Making (MADM); International Series in Operations Research \& Management Science; Springer International Publishing: Cham, Switzerland, 2019; ISBN 978-3-030-15008-2.

37. Schärlig, A. Décider Sur Plusieurs Critères, Panorama de l'aide à La Décision Multicritère; Presses Polytechniques et Universitaires Romandes: Lausanne, Switzerland, 1985.

38. Roy, B.; Giard, V.E. Méthodologie Multicritère d'Aide à La Décision; Editions Economica: Paris, France, 1985.

39. Fishburn, P.C. Utility Theory for Decision Making; Research Analysis Corporation: McLean, VA, USA, 1970.

40. Vincke, P. L'aide Multicritère à La Décision. Bull. Acad. R. Belg. 1991, 2, 147-151. [CrossRef]

41. Edwards, W. Social Utilities. Proceedings of a Symposium: Decision and Risk Analysis - Powerful New Tools for Management; U.S. Naval Academy: Annapolis, MD, USA, 1991.

42. Jacquet-Lagreze, E.; Siskos, J. Assessing a Set of Additive Utility Functions for Multicriteria Decision-Making, the UTA Method. Eur. J. Oper. Res. 1982, 10, 151-164. [CrossRef]

43. Hwang, C.L.; Yoon, K. Multiple Attribute Decision Making: Methods and Applications. A State-of-the-Art Survey; Lecture Notes in Economics and Mathematical Systems; Springer: Berlin/Heidelberg, Germany, 1981; p. 186.

44. Saaty, T.L. The Analytic Hierarchy Process; McGrow-Hill: New York, NY, USA, 1980.

45. Ignizio, J. A Reviw of Goal Programming: A Tool for Multiobjective Analysis. J. Operat. Res. Soc. 1978, 10, 151-164.

46. Stanujkic, D.; Karabasevic, D.; Zavadskas, E.K. A Framework for the Selection of a Packaging Design Based on the SWARA Method. Eng. Econ. 2015, 26, 181-187. [CrossRef]

47. Saaty, T.L.; Vargas, L.G. Models, Methods, Concepts \& Applications of the Analytic Hierarchy Process, 2nd ed.; International Series in Operations Research \& Management Science; Springer: New York, NY, USA, 2012; ISBN 978-1-4614-3596-9. 